\title{
Strategic Decision Selection Using Hesitant fuzzy TOPSIS and Interval Type-2 Fuzzy AHP: A case study
}

\author{
Sezi Cevik Onar \\ Istanbul Technical University Department of Industrial Engineering, \\ Istanbul, Beşiktaş, 34367, Turkey \\ Email:cevikse@itu.edu.tr \\ Bașar Oztaysi * \\ Istanbul Technical University Department of Industrial Engineering, \\ Istanbul, Beşiktaş, 34367, Turkey \\ Email:oztaysib@itu.edu.tr \\ Cengiz Kahraman \\ Istanbul Technical University Department of Industrial Engineering, \\ Istanbul, Beşiktaş, 34367, Turkey \\ Email:kahramanc@itu.edu.tr
}

Received 19 December 2013

Accepted 7 March 2014

\begin{abstract}
Strategic decisions such as mergers, acquisitions and joint ventures have a strong effect on firm performance. In order to be successful in highly competitive environments firms have to make right and on time strategic decisions. However, the nature of making the right strategic decision is complex and unstructured since there are many factors affecting such decisions. Moreover these factors are usually hard and vague to evaluate numerically. This study tries to develop a multicriteria decision-making model which considers both the complexity and vagueness of strategic decisions. The weights of the factors are determined by interval type-2 Fuzzy Analytic Hierarchy Process (AHP) and then the best strategy is selected by Hesitant Fuzzy TOPSIS using the determined weights. An application to a multinational consumer electronics company is presented.
\end{abstract}

Keywords: Hesitant Fuzzy Sets (HFS), TOPSIS, Interval Type-2 Fuzzy sets, AHP, Strategic Decision Making, Acquisitions and Mergers, Joint Ventures

*Corresponding author. 


\section{Introduction}

Over the past few decades due to the facts such as increasing globalization, technological developments and changes in the organization forms, the competition level has increased dramatically. This high level of competition caused high level of changes in the firms' environment and increased uncertainty for organizations of all types. In order to be successful in such turbulent environments firms should make right and on time strategic decisions to survive. Strategic decisions involve many organizational activities with risks and uncertainties ([1],[2]). Due to not only the environmental uncertainties but also the high number of organizational factors that should be taken into account, strategic decision making process is often considered as unstructured, uncertain and complex by nature [3].

In this study the investments such as mergers, acquisitions, joint ventures and non-equity alliances will be investigated. Each governance form has its own advantages and disadvantages. For instance, joint ventures enable the sharing of costs and risks with a partner. Since partners have different resources and competencies, it is easy to access to different resources such as technology, human, finance etc. On the other hand managing the partner relations can be complex especially when the motivations of the partners differ. Therefore a positive prior partnership relation or a low cultural difference among partners will increase the performance of a joint venture. Whereas a non-equity alliance will be a better choice if the partners try to build a new relation. Similarly an acquisition or merger may increase the knowledge resources and improve the business networks yet they're very complicated especially for the mergers. Defining branding strategies, joining forces, financing mergers and managing layoffs are the main challenges.

These strategic decisions have a significant effect on firm performance [4] and the selection of appropriate governance form (i.e. acquisition or joint venture) is one of the most important judgments a firm can make [5]. Therefore there are many studies focusing on these strategic decisions. These studies mainly focus on the performance of strategic decisions and try to reveal the factors affecting the firm decisions ([5];[6]). These factors are derived from different theories such as transaction cost or agency theory. Based on the literature, these factors can be grouped as environmental factors, firm related factors, target firm related factors, and decision related factors. Most of these factors are usually hard and vague to evaluate numerically. Unfortunately only a few studies in the literature show how these factors can be added to strategic decision making process. Also a group of managers usually give these strategic decisions which increase the complexity of the selection. We believe that an analytical method will contribute to the solution of this multi attribute and group decision making problem for strategic decision makers. Combining various perspectives of different decision makers is one of the biggest problems in such decisions since different decision makers have different expertise on different areas which limits the analytical methods on this field. This study tries to develop a multi criteria model which considers both the complexity and vagueness of the strategic decisions by combining different perspectives of decision makers.

Fuzzy sets are used to mathematically represent uncertainty and handle problems which contain imprecision [7]. They enable and present formalized tools for handling problems that contain imprecision so they are used in various engineering problems ([8],[9]). Just like many other methods, various MADM techniques are also extended to incorporate fuzzy sets for representing uncertainty and vagueness ([10],[11]). For the cases where more than one sources of vagueness exist, new generalizations of fuzzy sets are proposed for better modeling in the literature. Rodriguez [12] list these generalizations as: Type- 2 fuzzy sets, intuitionistic fuzzy sets, and fuzzy multisets and HFS. Among these generalizations HFS and Type-2 fuzzy sets are used in this paper. HFS are used to handle the situations where a set of values are possible for membership of a single element [13]. On the other hand, a type-2 fuzzy set [14], which is defined as a fuzzy set whose membership values themselves are also fuzzy sets can better handle uncertainties and vagueness.

In this paper, the strategic decision selection problem will be handled by using interval type- 2 fuzzy sets and HFS. The developed methodology will be applied to a multinational consumer electronics company. The originality of the paper comes from the first time integration of interval type- 2 fuzzy sets and HFS. The usage of this methodology for a strategic decision selection is also another originality of the paper. The motivation of this methodology is that it does not force decision makers to use either continuous or discrete 
fuzzy sets. In multi criteria decision making problems decision makers generally prefer assigning intervals for the criteria evaluation since pairwise comparisons between criteria are not based on measurable units. For instance the expression "criterion 1 is slightly stronger than criterion 2" can be easier represented via Type-2 fuzzy sets. On the other hand they prefer assigning a single score with a single membership degree for alternatives since alternative scores with respect to criteria can often be measured in units. For instance we can express a company's international joint venture decision experience level with a hesitant fuzzy set rather than a Type-2 fuzzy set. Interval type-2 fuzzy AHP let us compare the criteria using pairwise comparison matrices and continuous fuzzy sets and determine the weights of criteria whereas TOPSIS based on HFS evaluate alternatives using discrete fuzzy sets and it also allows us to collect possible scores for an alternative under a subcriterion with different perspectives. Thus our methodology provides a multicriteria evaluation using both continuous and discrete fuzzy sets.

The rest of the paper is organized as follows. Section 2 gives a literature review on strategic decision making, multiattribute decision making using HFS, and multiattribute decision making using interval type-2 fuzzy sets. Section 3 introduces the proposed methodology, which is composed of the integration of interval type-2 Fuzzy AHP and Fuzzy Hesitant TOPSIS. In Section 4, a real case study in a leading commercial electronics company in Turkey is given. Finally Section 5 gives the conclusions and future research suggestions.

\section{Literature Review}

\subsection{Strategic Decision Making}

Strategic decisions are one of the major determinants of the firm performance [15]. Due to this importance many researchers investigated the nature and process of strategic decisions [1] but these studies mainly focus on the behavioral factors that affect the judgment of strategic decision makers [16]. An analytical comprehensiveness approach increases the performance of strategic decisions [4]. The analytical studies that focus on strategy selection processes are limited.

There are a number of empirical studies that investigate the performance of strategic decisions but the results of these studies are controversial. For instance Kiymaz and K1lıc [17] in their empirical study on US firms showed that international merger and acquisition decisions increase the market value of the target firm whereas they decrease the market value of an acquiring firm. Contrarily Elfakhani et al. [18] in their study revealed that mergers yield a short term positive effect on performance of the acquiring firm. Jakobsen and Voetmann [19] showed that in the long term the acquiring Danish firms' performance is not below the market average.

These controversial results indicate that other indicators should be taken into account in order to explain the performance of strategic decisions. Several studies support this proposition. They investigated the effects of a singular factor on firm performance. For instance, Kiymaz and Mukherjee [20] showed that the origin of the target firm affects the performance of cross-border acquisitions. There are also studies indicating that not only due to the contingency factors but also the decision itself has a strong effect on firm performance: Zhang and Aldridge [21] analyzed effects of mergers and foreign alliance possibilities in the Canadian airline industry and showed that the alliance possibility for this industry creates higher performance when compared to mergers. Consequently in order to give the best strategic decisions the managers should also consider the contingency factors that affect the performance of strategic decisions. In literature there are studies that investigate not only the affect of one factor but also the affects of several factors on strategic decisions. Ji and Dimitratos [4] investigated the factors that affect the effectiveness of international entries and revealed that environmental factors such as uncertainty and munificence along with internal factors such as hierarchical centralization level affect the strategic decision performance. Walter et al. [22] investigated the interactive effects of decision process characteristics at the firm and alliance levels on alliance performance. The study shows that the success of a strategic decision depends on all the partners [22] and the relations among strategic decision partners should be considered. Wilcox et al. [23] investigated the effects of diversification level and the size of the firm on merger and acquisition performance in the US telecommunications industry. The results indicate that diversification level and size of the firm have a strong effect on acquisition performance. Although these empirical studies reveal the factors that affect the performance of strategic decisions, it was unclear how the managers would involve these factors in their strategic decision making process. The connections among these factors and the advantages and disadvantages of strategic decisions over these factors have not been revealed by these studies. Therefore an analytical method which will contribute to strategic decision making is crucial for strategic decision makers. In the literature there are several analytical studies on strategy selection but these studies either does not focus on governance form selection or does not show how the 
knowledge, international experience and financial condition are important factors for strategic decision selection processes. Therefore Partner firm's size (C31), Partner firm's product variety (C32), Partner firm's market knowledge (C33), Partner's international experience (C34) and Partner firm's financial condition (C35) are added to the strategic decision making model.

\subsubsection{Decision Related Factors}

The nature of the decision such as the prior experiences between the partners is also very important for the decision making process ([38];[39]). Table 3 summarizes decision related factors.

\section{Partner's similarity}

When the partners have similar products and supplementary resources it will increase the created value through the partner relations [40]. The different governance structures necessitate different partner relations.

\section{Prior relations}

Successful prior relations establish trust between partners. Therefore the partners will be willing to exchange their bonds [41]. Also prior relations between partners will ease the learning process and enable stronger relations between partners [42].

\section{Relatedness}

Relatedness which is defined as the distance between target industry and the focal firm's industry Folta and O'Brien [32] shows the knowledge level of the firm and may affect the strategy selection.

\section{Cultural distance}

Cultural distance between partners is an important determinant for the strategic decision performance. Depending on the strategy, greater cultural distance can have two controversial affects; it can either improve the learning mechanism Folta and Ferrier [43] or can create compatibility problems ([44]).
Table 3: Decision related factors

\begin{tabular}{ll}
\hline Decision Related Factors & Relevant studies \\
\hline Partners' similarity (C41) & {$[33] ;[30]$} \\
Prior relations (C42) & {$[41] ;[42]$} \\
Relatedness(C43) & {$[31] ;[32]$} \\
Cultural distance (C44) & {$[43] ;[40]$} \\
\hline
\end{tabular}

The relevant factors that affect the strategy selection decision are defined based on the literature review and a hierarchical model for strategic decision selection has been conducted (Figure 1). The model is modified by tree experts on this field, these experts are academicians and their working field of interest is strategic management.

\subsection{MADM using Hesitant Fuzzy Sets}

HFS has been increasingly used for multiattribute decision making problems in the recent years. Some of these works are given in the following:

Liu and Rodriguez [45] present a new representation of the hesitant fuzzy linguistic term sets (HFLTSs) by means of a fuzzy envelope to carry out the computing with words processes. They present an illustrative example of its application to a supplier selection problem through the use of fuzzy TOPSIS. Since computing with an envelope for HFLTS causes the loss of the initial fuzzy representation, the proposed fuzzy envelope is directly applied to fuzzy multicriteria decision making models and prevents this loss. However the complexity of the calculations is a disadvantage of this proposal. Peng et al. [46] present a generalized hesitant fuzzy synergetic weighted distance (GHFSWD) measure, which is based on the generalized hesitant fuzzy weighted distance (GHFWD) measure and the generalized hesitant fuzzy ordered weighted distance (GHFOWD) measure proposed by $\mathrm{Xu}$ and $\mathrm{Xia}$ [47] and investigate its some desirable properties and special cases. Based on the defined notions of positive ideal hesitant fuzzy set and negative ideal hesitant fuzzy set, they utilize the proposed GHFSWD measure to develop a method for multiple criteria decision making with hesitant fuzzy information. Even the usage of these measures is too cumbersome, this method is flexible since it allows decision makers to provide preference with hesitancy and determine different decision results by choosing different decision strategies. 


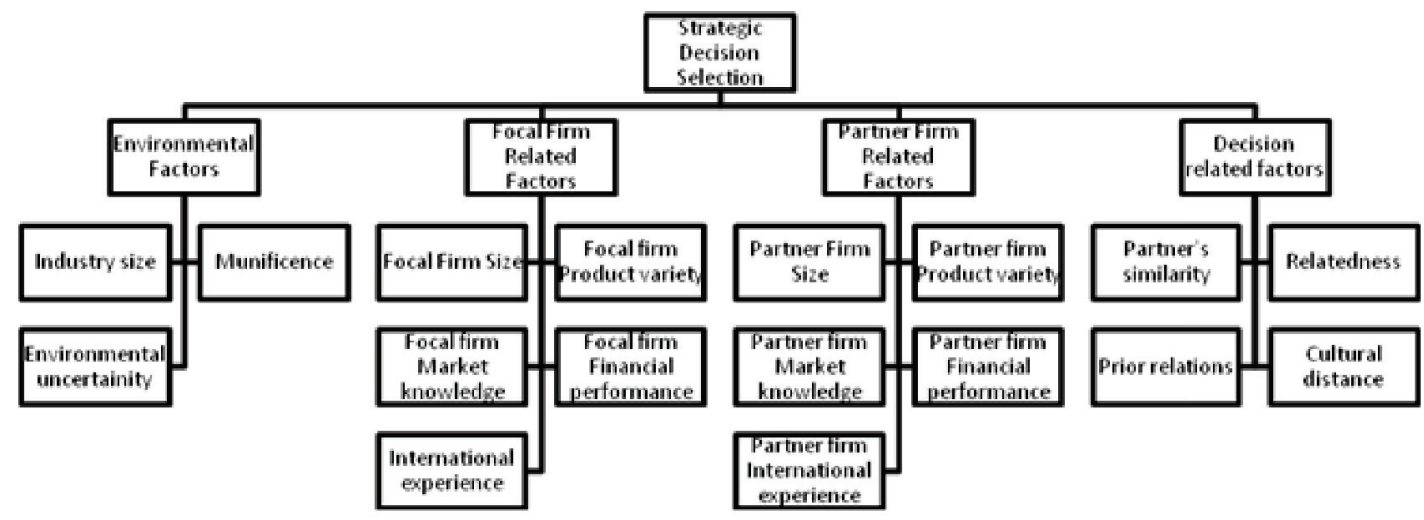

Figure 1: Strategic Decision Selection Model

The traditional hesitant fuzzy aggregation operators are generally suitable for aggregating the information taking the form of numerical values and they fail in dealing with hesitant interval-valued fuzzy information. Wei et al. [48] investigate the multiple attribute decision making (MADM) problems in which attribute values take the form of hesitant interval-valued fuzzy information. Firstly, definition and some operational laws of hesitant interval-valued fuzzy elements and score function of hesitant interval-valued fuzzy elements are introduced. Then, they develop some hesitant interval-valued fuzzy aggregation operators: hesitant interval-valued fuzzy weighted averaging (HIVFWA) operator, hesitant interval-valued fuzzy ordered weighted averaging (HIVFOWA) operator, the hesitant interval-valued fuzzy weighted geometric (HIVFWG) operator, hesitant interval-valued fuzzy ordered weighted geometric (HIVFOWG) operator, hesitant interval-valued fuzzy choquet ordered averaging (HIVFCOA) operator, hesitant intervalvalued fuzzy choquet ordered geometric (HIVFCOG) operator, hesitant interval-valued fuzzy prioritized aggregation operators and hesitant interval-valued fuzzy power aggregation operators. They apply the HIVFCOA and HIVFCOG operators to MADM with hesitant interval-valued fuzzy information. The important characteristic of the proposed operators is that they cannot only consider the importance of the elements or their ordered positions, but also reflect the correlation among the elements or their ordered positions.

In Wei et al.'s [48] approach, attribute values take the form of hesitant interval-valued fuzzy information. Zhao et al. [49] investigate the MADM problems in which attribute values take the form of hesitant triangular fuzzy information. They develop some hesitant triangular fuzzy aggregation operators based on the Einstein operation: the hesitant triangular fuzzy Einstein weighted averaging (HTFEWA) operator, hesitant triangular fuzzy Einstein weighted geometric (HTFEWG) operator, hesitant triangular fuzzy Einstein ordered weighted averaging (HTFEOWA) operator, hesitant triangular fuzzy Einstein ordered weighted geometric (HTFEOWG) operator, hesitant triangular fuzzy Einstein hybrid average (HTFEHA) operator and hesitant triangular fuzzy Einstein hybrid geometric (HTFEHG) operator.

Ye [50] propose a correlation coefficient between dual HFS as a new extension of existing correlation coefficients for HFS and intuitionistic fuzzy sets and apply it to MADM under dual hesitant fuzzy environments. Through the weighted correlation coefficient between each alternative and the ideal alternative, the ranking order of all alternatives is determined and the best alternative is easily identified. The proposed method provides a new idea for solving decision-making problems under the dual hesitant fuzzy environment.

Zhang [51] develops a wide range of hesitant fuzzy power aggregation operators for hesitant fuzzy information. He first introduces several power aggregation operators and then extends these operators to hesitant fuzzy environments. He demonstrates several useful properties of the operators and discusses the relationships between them. The new aggregation operators are utilized to develop techniques for multiple attribute group decision making with hesitant fuzzy information. Compared to the previous approaches to multiple group decision making with hesitant fuzzy information, the advantage of this approach is that the 
associated weights are determined using the support measure. Thus it reduces the influence of excessively high or low arguments on the decision result.

Wei [52] investigates the hesitant fuzzy MADM problems in which the attributes are in different priority level. Motivated by the ideal of prioritized aggregation operators developed by Yager [53], he develops some prioritized aggregation operators for aggregating hesitant fuzzy information, and then applies them to develop some models for hesitant fuzzy MADM problems in which the attributes are in different priority level. The main advantages of the proposed operators and approaches over the traditional hesitant fuzzy operators and approaches are that they not only accommodate the hesitant fuzzy environment but also consider the prioritization among the attributes.

$\mathrm{Xu}$ and Xia [54] introduce the concepts of entropy and cross-entropy for hesitant fuzzy information, and discuss their desirable properties. They develop several measure formulas and analyze the relationships among the proposed entropy, cross-entropy, and similarity measures. They can find that these measures are interchangeable under certain conditions. Then they develop two multiattribute decision-making methods in which the attribute values are given in the form of HFS reflecting humans' hesitant thinking comprehensively. In one method, the weight vector is determined by the hesitant fuzzy entropy measure, and the optimal alternative is obtained by comparing the hesitant fuzzy cross-entropies between the alternatives and the ideal solutions; in the other method, the weight vector is derived from the maximizing deviation method and the optimal alternative is obtained by using the TOPSIS method. Since this paper develops some entropy and cross-entropy measures for HFS, it is an important paper for hesitant fuzzy decision making.

Rodriguez et al. [12] introduce the concept of a HFLTS to provide a linguistic and computational basis to increase the richness of linguistic elicitation based on the fuzzy linguistic approach and the use of context-free grammars by using comparative terms. Then, a multicriteria linguistic decision-making model is presented in which experts provide their assessments by eliciting linguistic expressions. This decision model manages such linguistic expressions by means of its representation using HFLTSs. This paper allows us to use different expressions to represent decision makers' knowledge/preferences in decision making.

Type-2 fuzzy sets are also increasingly used in multiattribute decision making problems because of their ability in defining membership functions.

Chen et al. [55] develop an extended QUALIFLEX method for handling multiple criteria decision-making problems in the context of interval type-2 fuzzy sets. QUALIFLEX, a generalization of Jacquet-Lagreze's permutation method, is a useful outranking method in decision analysis because of its flexibility with respect to cardinal and ordinal information. Using the linguistic rating system converted into interval type- 2 trapezoidal fuzzy numbers, the extended QUALIFLEX method investigates all possible permutations of the alternatives with respect to the level of concordance of the complete preference order. Based on a signed distance-based approach, they propose the concordance/discordance index, the weighted concordance/discordance index, and the comprehensive concordance/discordance index as evaluative criteria of the chosen hypothesis for ranking the alternatives. This paper is important since it first time extends QUALIFLEX using type-2 fuzzy sets. Chen [56] develops an interactive method for handling multiple criteria group decision-making problems, in which information about criteria weights is incompletely (imprecisely or partially) known and the criteria values are expressed as interval type-2 trapezoidal fuzzy numbers. With respect to the relative importance of multiple decision-makers and group consensus of fuzzy opinions, a hybrid averaging approach combining weighted averages and ordered weighted averages is employed to construct the collective decision matrix. An integrated programming model is then established based on the concept of signed distance-based closeness coefficients to determine the importance weights of criteria and the priority ranking of alternatives. Chen [57] develops a new linear assignment method to produce an optimal preference ranking of the alternatives in accordance with a set of criterion-wise rankings and a set of criterion importance within the context of interval type2 trapezoidal fuzzy numbers. Applying the proposed method to a case involving the selection of a landfill site, he demonstrates that the proposed method is easy to employ and that it produces actionable results that aid the decision-making process. The proposed interval type-2 fuzzy linear assignment method utilizes signed distances and does not require a complicated computation procedure.

Wang et al. [58] investigate the group decision making problems in which all the information provided by the decision makers (DMs) is expressed as interval type-2 fuzzy decision matrices, and the information about attribute weights is partially known, which may be constructed by various forms. They first use the interval type-2 fuzzy weighted arithmetic averaging operator to aggregate all individual interval type-2 fuzzy decision matrices provided by the DMs into the collective interval type-2 fuzzy decision matrix, then they utilize the ranking-value measure to calculate the ranking value of each attribute value and construct the rankingvalue matrix of the collective interval type- 2 fuzzy decision matrix. Based on the ranking-value matrix and 
the given attribute weight information, they establish some optimization models to determine the weights of attributes.

Chen and Lee [59] present a new method for handling fuzzy multiple criteria hierarchical group decisionmaking problems based on arithmetic operations and fuzzy preference relations of interval type- 2 fuzzy sets. Because the time complexity of the proposed method is $\mathrm{O}(\mathrm{nk})$, where $\mathrm{n}$ is the number of criteria and $\mathrm{k}$ is the number of decision-makers, it is more efficient than $\mathrm{Wu}$ and Mendel's method, whose time complexity is $\mathrm{O}$ (mnk), where $\mathrm{m}$ is the number of $\alpha$-cuts, $\mathrm{n}$ is the number of criteria and $\mathrm{k}$ is the number of decisionmakers.

Balezentis and Zeng [60] extend the MULTIMOORA method with type-2 fuzzy sets, generalized intervalvalued trapezoidal fuzzy numbers. The proposed method thus provides the means for multi-criteria decision making related to uncertain assessments. Utilization of aggregation operators also enables to facilitate group multi-criteria decision making.

Çelik et al. [61] address the problems of public transportation customers in Istanbul and their satisfaction levels are evaluated by using customer satisfaction survey and statistical analysis. A novel interval type-2 fuzzy MADM method is proposed based on TOPSIS and GRA, to evaluate and improve customer satisfaction in Istanbul public transportation. The proposed integrated novel MADM benefits from the advantages of combining GRA, TOPSIS and type-2 fuzzy sets.

To the best of our knowledge, there is no work on strategic decision selection using an integrated methodology of type-2 fuzzy AHP and hesitant fuzzy TOPSIS in the literature. Our methodology provides a flexibility to define membership functions and membership degrees through type- 2 fuzzy sets and HFS, respectively.

\subsection{Interval Type-2 Fuzzy Sets}

In ordinary (type-1) fuzzy sets [7],each element of a set has a degree of membership which is described by a membership function and can take any value in the interval $[0,1]$. Type-2 fuzzy sets are proposed by Zadeh [14] having this membership value as fuzzy numbers themselves can better handle uncertainties and vagueness. Mendel and John [62] state that the membership functions of type-1 fuzzy sets are twodimensional however membership functions of type-2 fuzzy sets are three-dimensional and this new third dimension provides additional degrees of freedom that make it possible to directly model uncertainties
A type-2 fuzzy set $\widetilde{\widetilde{A}}$ in the universe of discourse $\mathrm{X}$ can be represented by a type- 2 membership function $\mu_{\widetilde{\mathrm{A}}}(\mathrm{x}, \mathrm{u})$, where $\mathrm{x} \in \mathrm{X}$ and $\mathrm{u} \in \mathrm{J}_{\mathrm{X}} \subseteq[0,1]$ as follows [14];

$$
\begin{aligned}
& \widetilde{\widetilde{A}}=\left\{\left((x, u), \mu_{\widetilde{\mathrm{A}}}(x, u)\right) \mid \forall x \in X, \forall u \in J_{x} \subseteq[0,1], 0 \leq\right. \\
& \left.\mu_{\widetilde{\mathrm{A}}}(x, u) \leq 1\right\},
\end{aligned}
$$

where $\mathrm{J}_{\mathrm{X}}$ denotes an interval $[0,1]$. The type-2 fuzzy set $\widetilde{\widetilde{A}}$ also can be represented as follows [63]:

$\widetilde{\widetilde{A}}=\int_{\mathrm{x} \in \mathrm{X}} \int_{\mathrm{u} \in \mathrm{J}_{\mathrm{X}}} \mu_{\widetilde{\mathrm{A}}}(\mathrm{x}, \mathrm{u}) /(\mathrm{x}, \mathrm{u}) \quad \mathrm{J}_{\mathrm{x}} \subseteq[0,1]$

where $\mathrm{J}_{\mathrm{x}} \subseteq[0,1]$ and $\iint$ denote union over all admissible $\mathrm{x}$ and $\mathrm{u}$.

Interval type-2 fuzzy set [64] are the special case of this definition where $\mu_{\widetilde{\mathrm{A}}}(\mathrm{x}, \mathrm{u})=1$. Based on this definition, trapezoidal interval type-2 fuzzy set represents are represented as follows [63]:

$\widetilde{\widetilde{A}}_{\mathrm{i}}=\left(\widetilde{\mathrm{A}}_{\mathrm{i}}^{\mathrm{U}} ; \widetilde{\mathrm{A}}_{\mathrm{i}}^{\mathrm{L}}\right)=$

$\left(\left(a_{i 1}^{\mathrm{U}}, \mathrm{a}_{\mathrm{i} 2}^{\mathrm{U}}, \mathrm{a}_{\mathrm{i} 3}^{\mathrm{U}}, \mathrm{a}_{\mathrm{i} 4}^{\mathrm{U}} ; \mathrm{H}_{1}\left(\widetilde{\mathrm{A}}_{\mathrm{i}}^{\mathrm{U}}\right), \mathrm{H}_{2}\left(\widetilde{\mathrm{A}}_{\mathrm{i}}^{\mathrm{U}}\right)\right),\left(\begin{array}{c}\mathrm{a}_{\mathrm{i} 1}^{\mathrm{L}}, \mathrm{a}_{\mathrm{i} 2}^{\mathrm{L}}, \mathrm{a}_{\mathrm{i} 3}^{\mathrm{L}}, \mathrm{a}_{\mathrm{i} 4}^{\mathrm{L}} ; \\ \mathrm{H}_{1}\left(\widetilde{\mathrm{A}}_{\mathrm{i}}^{\mathrm{L}}\right), \mathrm{H}_{2}\left(\widetilde{\mathrm{A}}_{\mathrm{i}}^{\mathrm{L}}\right)\end{array}\right)\right)$

where $\widetilde{\mathrm{A}}_{\mathrm{i}}^{\mathrm{U}}$ and $\widetilde{\mathrm{A}}_{\mathrm{i}}^{\mathrm{L}}$ are type- 1 fuzzy sets; $\mathrm{a}_{\mathrm{i} 1}^{\mathrm{U}}, \mathrm{a}_{\mathrm{i} 2}^{\mathrm{U}}, \mathrm{a}_{\mathrm{i} 3}^{\mathrm{U}}$, $\mathrm{a}_{\mathrm{i} 4}^{\mathrm{U}}, \mathrm{a}_{\mathrm{i} 1}^{\mathrm{L}}, \mathrm{a}_{\mathrm{i} 2}^{\mathrm{L}}, \mathrm{a}_{\mathrm{i} 3}^{\mathrm{L}}$ and $\mathrm{a}_{\mathrm{i} 4}^{\mathrm{L}}$ are the references points of the interval type-2 fuzzy set $\widetilde{\widetilde{A}}_{i}, H_{j}\left(\widetilde{A}_{i}^{U}\right)$; shows the membership value of the element $a_{j(j+1)}^{U}$ in the upper trapezoidal membership function $\left(\widetilde{\mathrm{A}}_{\mathrm{i}}^{\mathrm{U}}\right), 1 \leq \mathrm{j} \leq 2$, $\mathrm{H}_{\mathrm{j}}\left(\widetilde{\mathrm{A}}_{\mathrm{i}}^{\mathrm{L}}\right)$ denotes the membership value of the element $\mathrm{a}_{\mathrm{j}(\mathrm{j}+1)}^{\mathrm{L}}$ in the lower trapezoidal membership function $\widetilde{\mathrm{A}}_{\mathrm{i}}^{\mathrm{L}}$, $1 \leq \mathrm{j} \leq 2$ [65].

Figure 2 represents a sample trapezoidal interval type- 2 fuzzy set

$((5,10,25,45 ; 0.90,1),(10,15,25,40 ; 0.40,0.60))$.

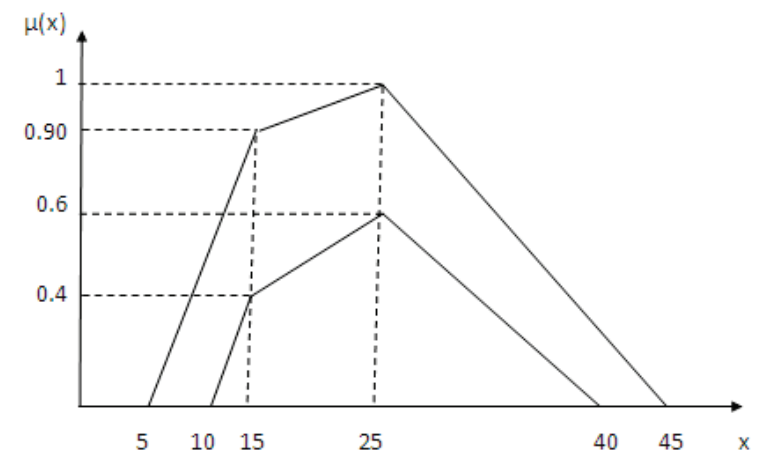

Figure 2: Interval Type-2 Fuzzy sets

For the purpose of representing the arithmetic operations on type- 2 fuzzy sets, assume $\mathrm{k}$ is a crisp 
number and $\widetilde{\mathrm{A}}_{1}, \widetilde{\mathrm{A}}_{2}$ are interval type-2 fuzzy sets as given in the following:

$\widetilde{\mathrm{A}}_{1}=$

$\left(\left(\mathrm{a}_{11}^{\mathrm{U}}, \mathrm{a}_{12}^{\mathrm{U}}, \mathrm{a}_{13}^{\mathrm{U}}, \mathrm{a}_{14}^{\mathrm{U}} ; \mathrm{H}_{1}\left(\widetilde{\mathrm{A}}_{1}^{\mathrm{U}}\right), \mathrm{H}_{2}\left(\widetilde{\mathrm{A}}_{1}^{\mathrm{U}}\right)\right),\left(\mathrm{a}_{11}^{\mathrm{L}}, \mathrm{a}_{12}^{\mathrm{L}}, \mathrm{a}_{13}^{\mathrm{L}}, \mathrm{a}_{14}^{\mathrm{L}}, \mathrm{H}_{1}\left(\widetilde{\mathrm{A}}_{1}^{\mathrm{L}}\right), \mathrm{H}_{2}\left(\widetilde{\mathrm{A}}_{1}^{\mathrm{L}}\right)\right)\right.$

$\widetilde{\mathrm{A}}_{2}=\left(\left(\mathrm{a}_{21}^{\mathrm{U}}, \mathrm{a}_{22}^{\mathrm{U}}, \mathrm{a}_{23}^{\mathrm{U}}, \mathrm{a}_{24}^{\mathrm{U}} ; \mathrm{H}_{1}\left(\widetilde{\mathrm{A}}_{2}^{\mathrm{U}}\right), \mathrm{H}_{2}\left(\widetilde{\mathrm{A}}_{2}^{\mathrm{U}}\right)\right)\right.$,

$\left.\left(\mathrm{a}_{21}^{\mathrm{L}}, \mathrm{a}_{22}^{\mathrm{L}}, \mathrm{a}_{23}^{\mathrm{L}}, \mathrm{a}_{24}^{\mathrm{L}} ; \mathrm{H}_{1}\left(\widetilde{\mathrm{A}}_{2}^{\mathrm{L}}\right), \mathrm{H}_{2}\left(\widetilde{\mathrm{A}}_{2}^{\mathrm{L}}\right)\right)\right)$

Chen and Lee [65] gives the arithmetic operations with these numbers are follows:

$$
\begin{aligned}
& \text { Addition: } \quad \widetilde{\widetilde{A}}_{1} \oplus \widetilde{\widetilde{A}}_{2}=\left(\left(\mathrm{a}_{11}^{\mathrm{U}}+\mathrm{a}_{21}^{\mathrm{U}}, \mathrm{a}_{12}^{\mathrm{U}}+\mathrm{a}_{22}^{\mathrm{U}}, \mathrm{a}_{13}^{\mathrm{U}}+\right.\right. \\
& \begin{array}{r}
\mathrm{a}_{23}^{\mathrm{U}}, \mathrm{a}_{14}^{\mathrm{U}}+\mathrm{a}_{24}^{\mathrm{U}} ; \\
\left.\min \left(\mathrm{H}_{1}\left(\widetilde{\mathrm{A}}_{1}^{\mathrm{U}}\right) ; \mathrm{H}_{1}\left(\widetilde{\mathrm{A}}_{2}^{\mathrm{U}}\right)\right), \min \left(\mathrm{H}_{2}\left(\widetilde{\mathrm{A}}_{1}^{\mathrm{U}}\right) ; \mathrm{H}_{2}\left(\widetilde{\mathrm{A}}_{2}^{\mathrm{U}}\right)\right)\right),\left(\mathrm{a}_{11}^{\mathrm{L}}\right. \\
+\mathrm{a}_{21}^{\mathrm{L}}, \mathrm{a}_{12}^{\mathrm{L}}+\mathrm{a}_{22}^{\mathrm{L}}, \mathrm{a}_{13}^{\mathrm{L}}+\mathrm{a}_{23}^{\mathrm{L}}, \mathrm{a}_{14}^{\mathrm{L}}+\mathrm{a}_{24}^{\mathrm{L}} ; \\
\left.\left.\min \left(\mathrm{H}_{1}\left(\widetilde{\mathrm{A}}_{1}^{\mathrm{L}}\right) ; \mathrm{H}_{1}\left(\widetilde{\mathrm{A}}_{2}^{\mathrm{L}}\right)\right), \min \left(\mathrm{H}_{2}\left(\widetilde{\mathrm{A}}_{1}^{\mathrm{L}}\right) ; \mathrm{H}_{2}\left(\widetilde{\mathrm{A}}_{2}^{\mathrm{L}}\right)\right)\right)\right)
\end{array}
\end{aligned}
$$

Subtraction: $\widetilde{\mathrm{A}}_{1} \ominus \widetilde{\widetilde{A}}_{2}=\left(\left(\mathrm{a}_{11}^{\mathrm{U}}-\mathrm{a}_{24}^{\mathrm{U}}, \mathrm{a}_{12}^{\mathrm{U}}-\mathrm{a}_{23}^{\mathrm{U}}, \mathrm{a}_{13}^{\mathrm{U}}-\right.\right.$ $\mathrm{a}_{22}^{\mathrm{U}}, \mathrm{a}_{14}^{\mathrm{U}}-$

$\left.\mathrm{a}_{21}^{\mathrm{U}} ; \min \left(\mathrm{H}_{1}\left(\widetilde{\mathrm{A}}_{1}^{\mathrm{U}}\right) ; \mathrm{H}_{1}\left(\widetilde{\mathrm{A}}_{2}^{\mathrm{U}}\right)\right), \min \left(\mathrm{H}_{2}\left(\widetilde{\mathrm{A}}_{1}^{\mathrm{U}}\right) ; \mathrm{H}_{2}\left(\widetilde{\mathrm{A}}_{2}^{\mathrm{U}}\right)\right)\right),\left(\mathrm{a}_{11}^{\mathrm{L}}-\right.$ $\mathrm{a}_{24}^{\mathrm{L}}, \mathrm{a}_{12}^{\mathrm{L}}-\mathrm{a}_{23}^{\mathrm{L}}, \mathrm{a}_{13}^{\mathrm{L}}-\mathrm{a}_{22}^{\mathrm{L}}, \mathrm{a}_{14}^{\mathrm{L}}-\mathrm{a}_{21}^{\mathrm{L}}$;

$\left.\left.\min \left(\mathrm{H}_{1}\left(\widetilde{\mathrm{A}}_{1}^{\mathrm{L}}\right) ; \mathrm{H}_{1}\left(\widetilde{\mathrm{A}}_{2}^{\mathrm{L}}\right)\right), \min \left(\mathrm{H}_{2}\left(\widetilde{\mathrm{A}}_{1}^{\mathrm{L}}\right) ; \mathrm{H}_{2}\left(\widetilde{\mathrm{A}}_{2}^{\mathrm{L}}\right)\right)\right)\right)$

Multiplication: $\quad \widetilde{\mathrm{A}}_{1} \otimes \widetilde{\mathrm{A}}_{2} \cong\left(\left(\mathrm{a}_{11}^{\mathrm{U}} \times \mathrm{a}_{21}^{\mathrm{U}}, \mathrm{a}_{12}^{\mathrm{U}} \times \mathrm{a}_{22}^{\mathrm{U}}, \mathrm{a}_{13}^{\mathrm{U}} \times\right.\right.$ $\mathrm{a}_{23}^{\mathrm{U}}, \mathrm{a}_{14}^{\mathrm{U}} \times \mathrm{a}_{24}^{\mathrm{U}}$

$\left.\min \left(\mathrm{H}_{1}\left(\widetilde{\mathrm{A}}_{1}^{\mathrm{U}}\right) ; \mathrm{H}_{1}\left(\widetilde{\mathrm{A}}_{2}^{\mathrm{U}}\right)\right), \min \left(\mathrm{H}_{2}\left(\widetilde{\mathrm{A}}_{1}^{\mathrm{U}}\right) ; \mathrm{H}_{2}\left(\widetilde{\mathrm{A}}_{2}^{\mathrm{U}}\right)\right)\right),\left(\left(\mathrm{a}_{11}^{\mathrm{L}} \times \mathrm{a}_{21}^{\mathrm{L}}, \mathrm{a}_{12}^{\mathrm{L}} \times\right.\right.$ $\mathrm{a}_{22}^{\mathrm{L}}, \mathrm{a}_{13}^{\mathrm{L}} \times \mathrm{a}_{23}^{\mathrm{L}}, \mathrm{a}_{14}^{\mathrm{L}} \times$

$\left.\left.\mathrm{a}_{24}^{\mathrm{L}} ; \min \left(\mathrm{H}_{1}\left(\widetilde{\mathrm{A}}_{1}^{\mathrm{L}}\right) ; \mathrm{H}_{1}\left(\widetilde{\mathrm{A}}_{2}^{\mathrm{L}}\right)\right), \min \left(\mathrm{H}_{2}\left(\widetilde{\mathrm{A}}_{1}^{\mathrm{L}}\right) ; \mathrm{H}_{2}\left(\widetilde{\mathrm{A}}_{2}^{\mathrm{L}}\right)\right)\right)\right)$

\section{Multiplication with a crisp number:}

$\mathrm{k} \widetilde{\mathrm{A}}_{1}=\left(\left(\mathrm{k} \times \mathrm{a}_{11}^{\mathrm{U}}, \mathrm{k} \times \mathrm{a}_{12}^{\mathrm{U}}, \mathrm{k} \times \mathrm{a}_{13}^{\mathrm{U}}, \mathrm{k} \times \mathrm{a}_{14}^{\mathrm{U}}\right) ; \mathrm{H}_{1}\left(\widetilde{\mathrm{A}}_{1}^{\mathrm{U}}\right), \mathrm{H}_{2}\left(\widetilde{\mathrm{A}}_{1}^{\mathrm{U}}\right)\right.$,

$$
\left.\left(\mathrm{k} \times \mathrm{a}_{11}^{\mathrm{L}}, \mathrm{k} \times \mathrm{a}_{12}^{\mathrm{L}}, \mathrm{k} \times \mathrm{a}_{13}^{\mathrm{L}}, \mathrm{k} \times \mathrm{a}_{14}^{\mathrm{L}} ; \mathrm{H}_{1}\left(\widetilde{\mathrm{A}}_{1}^{\mathrm{L}}\right), \mathrm{H}_{2}\left(\widetilde{\mathrm{A}}_{1}^{\mathrm{L}}\right)\right)\right)
$$

\section{Division:}

$\frac{\tilde{\tilde{a}}_{i j}}{\tilde{\tilde{b}}_{i j}}=\left(\frac{a_{1}^{u}}{b_{4}^{u}}, \frac{a_{2}^{u}}{b_{3}^{u}}, \frac{a_{3}^{u}}{b_{2}^{u}}, \frac{a_{4}^{u}}{b_{1}^{u}}, \min \left(H_{1}^{u}(a), H_{1}^{u}(b)\right), \min \left(H_{2}^{u}(a), H_{2}^{u}(b)\right)\right)$

$\left(\frac{a_{1}^{L}}{b_{4}^{L}}, \frac{a_{2}^{L}}{b_{3}^{L}}, \frac{a_{3}^{L}}{b_{2}^{L}}, \frac{a_{4}^{L}}{b_{1}^{L}}, \min \left(H_{1}^{L}(a), H_{1}^{L}(b)\right), \min \left(H_{2}^{L}(a), H_{2}^{L}(b)\right)\right)$

Division by a crisp number:

$$
\begin{aligned}
& \frac{\widetilde{\mathrm{A}}_{1}}{\mathrm{k}}=\left(\left(\frac{1}{\mathrm{k}} \times \mathrm{a}_{11}^{\mathrm{U}}, \frac{1}{\mathrm{k}} \times \mathrm{a}_{12}^{\mathrm{U}}, \frac{1}{\mathrm{k}} \times \mathrm{a}_{13}^{\mathrm{U}}, \frac{1}{\mathrm{k}} \times \mathrm{a}_{14}^{\mathrm{U}}\right) ; \mathrm{H}_{1}\left(\widetilde{\mathrm{A}}_{1}^{\mathrm{U}}\right), \mathrm{H}_{2}\left(\widetilde{\mathrm{A}}_{1}^{\mathrm{U}}\right),\right. \\
& \left.\left(\frac{1}{\mathrm{k}} \times \mathrm{a}_{11}^{\mathrm{L}}, \frac{1}{\mathrm{k}} \times \mathrm{a}_{12}^{\mathrm{L}}, \frac{1}{\mathrm{k}} \times \mathrm{a}_{13}^{\mathrm{L}}, \frac{1}{\mathrm{k}} \times \mathrm{a}_{14}^{\mathrm{L}} ; \mathrm{H}_{1}\left(\widetilde{\mathrm{A}}_{1}^{\mathrm{L}}\right), \mathrm{H}_{2}\left(\widetilde{\mathrm{A}}_{1}^{\mathrm{L}}\right)\right)\right)
\end{aligned}
$$

where $\mathrm{k}>0$.

\subsection{Hesitant Fuzzy Sets}

HFS, initially developed by Torra [13] are the extensions of regular fuzzy sets which handle the situations where a set of values are possible for the membership of a single element [12]. Torra and Narukawa [66] state the difficulty of determining the membership value of an element on a set and specify that HFS can be used in cases where uncertainty on the possible membership values are limited such as; a group of experts may not agree on the membership of an element and discuss it to be whether 0.5 or 0.6 . In such cases HFS can represent the situation and instead of using an aggregation operator to get a single value, it is useful to deal with all the possible values [13]. In general, in different levels of decision making process, people may have hesitancy in providing their preferences, in these situations HFS can be used to represent the preferences [67].

Torra [13] defines HFS as follow: Let X be a fixed set, a HFS on $\mathrm{X}$ is in terms of a function that when applied to $X$ returns a subset of $[0,1]$. Mathematical expression for HFS is as follows:

$$
E=\left\{<x, h_{E}(x)>\mid x \in X\right\},
$$

where $h_{E}(x)$ is a set of some values in $[0,1]$, denoting the possible membership degrees of the element $x \in X$ to the set E. Xia and Xu [68] call $h=h_{E}(x)$ a hesitant fuzzy element (HFE).

Some basic definitions about $\mathrm{h}$, is given in the following;

The upper and lower bound of $\mathrm{h}$ is given as;

$h^{-}(x)=\min h(x)$;

$h^{+}(x)=\max h(x)$;

The compliment of $\mathrm{h}$ is shown as $\mathrm{h}^{\mathrm{c}}$ and is given as

$h^{c}=\cup_{\gamma \in h}\{1-\gamma\}$;

The envelope of $\mathrm{h}, \mathrm{A}_{\mathrm{env}(\mathrm{h})}$, is an intuitionistic fuzzy set which is defined as

$$
\begin{gathered}
A_{\text {env(h) }} \\
\text { where }
\end{gathered}
$$

$$
\begin{aligned}
& \mu(x)=h^{-}(x) . . \\
& v(x)=1-h^{+}(x)
\end{aligned}
$$

Let $h, h_{1}$ and $h_{2}$ be three HFEs, then basic operations on these elements are given as follows [69]:

$$
\begin{aligned}
& h^{\lambda}=\cup_{\gamma \in h}\left\{\gamma^{\lambda}\right\} ; \\
& \lambda h=\cup_{\gamma \in h}\left\{1-(1-\gamma)^{\lambda}\right\} ; \\
& h_{1} \cup h_{2}=\cup_{\gamma_{1} \in h_{1}, \gamma_{2} \in h_{2}}, \max \left\{\gamma_{1}, \gamma_{2}\right\} ; \\
& h_{1} \cap h_{2}=\cup_{\gamma_{1} \in h_{1}, \gamma_{2} \in h_{2}}, \min \left\{\gamma_{1}, \gamma_{2}\right\} ; \\
& h_{1} \oplus h_{2}=\cup_{\gamma_{1} \in h_{1}, \gamma_{2} \in h_{2},}\left\{\gamma_{1}+\gamma_{2}-\gamma_{1} \gamma_{2}\right\} ; \\
& h_{1} \otimes h_{2}=\cup_{\gamma_{1} \in h_{1}, \gamma_{2} \in h_{2},}\left\{\gamma_{1} \gamma_{2}\right\} ;
\end{aligned}
$$

In the scope of this study one of the most important operation is about finding the distance between two HFEs. The literature provides different approaches for 
this purpose. While Xu and Xia [47] define the hesitant Euclidean distance as:

$d_{1}\left(h_{1}, h_{2}\right)=\sqrt{\frac{1}{l} \sum_{i=1}^{l}\left|h_{1_{\sigma(i)}}-h_{2_{\sigma(i)}}\right|^{2}}$

Zhang and Wei (2013) propose Hamming distance measure as:

$d_{1}\left(h_{1}, h_{2}\right)=\frac{1}{l} \sum_{i=1}^{l}\left|h_{1_{\sigma(i)}}-h_{2_{\sigma(i)}}\right|$

where $h_{1}, h_{2}$ are HFEs and $l$ is the number of elements in a HFE, which is called length. However, the length of HFEs may be different and the values are usually out of order. Then initially the elements should be ordered in an increasing or decreasing order, and then if the lengths are different, i.e. $l_{h_{1}}<l_{h_{2}}$ then $h_{1}$ should be extended by adding the minimal value in it until it has the same number of elements. The shorter one can also be extended depending on decision makers' risk preferences. Optimists anticipate desirable outcomes and may add the maximum value, while pessimists expect unfavorable outcomes and may add the minimal value [67].

\section{Methodology: Interval Type-2 Fuzzy AHP and Fuzzy Hesitant TOPSIS}

The fuzzy set theory initially developed by Zadeh [7] enables mathematical representation of uncertainty and present formalized tools for handling problems that contain imprecision. As fuzzy sets enable representation of knowledge in a more natural way, they are used in many engineering and decision problems. In the literature, many crisp analysis methods are extended using fuzzy sets to strengthen solving real-world problems. In multi criteria decision making area, various techniques are also extended to use linguistic variables to achieve this benefit. These linguistic values are characterized by fuzzy sets using several mapping functions including, triangular, trapezoidal and Sshaped membership functions are being used in the literature [70].

However, to deal with imprecise information where more than one sources of vagueness appear simultaneously, ordinary fuzzy sets may encounter problems with modeling the situation [12]. In order to handle such situations different generalizations and extensions of fuzzy sets have been introduced. Interval type-2 fuzzy sets and HFS are two such important generalizations that are used in this study. Interval type2 fuzzy sets can incorporate uncertainty about the membership function in their definition and HFS manages the situations where a set of values are possible for membership of an element. In this section interval type-2 fuzzy AHP and Hesitant fuzzy TOPSIS methods are explained and integrated methodology is introduced.

\subsection{Interval Type-2 Fuzzy AHP}

AHP is a multicriteria decision making technique initially developed by Saaty [71]. In AHP methodology, the problem is structured as a hierarchy of criteria and alternatives take place at the final level. For each level, relative weights of criteria and alternatives are calculated by pairwise comparisons. Decision makers use a linguistic scale to make judgments about pairwise comparisons. In classical AHP approach the linguistic scale consists of linguistic terms and a number between one and nine associated with this linguistic variable. However, this scale is later extended to triangular and trapezoidal fuzzy numbers also the methodology is extended to operate with fuzzy numbers.

In the literature there are various Approaches to integrate fuzzy numbers with AHP. In the initial study in this area, Laarhoven and Pedrycz [72] propose the first algorithm in fuzzy AHP by using triangular fuzzy membership functions and Lootsma's logarithmic least square method. Later, Buckley [64] extends the method with trapezoidal fuzzy numbers and proposes geometric mean method to derive fuzzy weights from pairwise comparisons. Chang [73] proposes the extent analysis method for the synthetic extent values of the pairwise comparisons. In one of the recent studies Zeng et al. [74] propose using arithmetic averaging method to get performance scores and extend the method with different scales contains triangular, trapezoidal, and crisp numbers.

Because of their ability to handle uncertainties and vagueness in a better way, type-2 fuzzy sets has a great potential to integrate with AHP method. Kahraman et al. [75] propose a methodology for interval type-2 fuzzy AHP. Chiao [76] suggests a methodology for integrating trapezoidal interval type-2 fuzzy sets and Sari et al. [77] apply interval type-2 fuzzy sets on warehouse selection problem in group decision making environment. Based on Buckley's [64] fuzzy AHP method and initial studies the extended procedure of the interval type-2 fuzzy AHP method is given in the following:

Step 1: Defining the problem and establishing the hierarchy, goal being at the top, criteria and sub-criteria in the intermediate level and alternatives at the lowest level.

Step 2: Constructing pairwise comparison matrices and collecting expert judgments using trapezoidal interval type-2 fuzzy scales used in the study are given in Table 4 [77]. In this study since AHP is only used to determine the weights, the alternatives do not take place in the hierarchy and in the pairwise comparison matrices. 
Table 4. Definition and interval type 2 fuzzy scales of the linguistic variables

$$
\tilde{\tilde{a}}_{i j}=\left[\tilde{\tilde{a}}_{i j}^{1} \otimes \ldots \otimes \tilde{\tilde{a}}_{i j}^{n}\right]^{1 / n}
$$

\begin{tabular}{ll}
\hline Linguistic variables & $\begin{array}{l}\text { Trapezoidal Interval Type-2 } \\
\text { fuzzy scales }\end{array}$ \\
\hline Absolutely Strong (AS) & $(7,8,9,9 ; 1,1)$, \\
& $(7.2,8.2,8.8,9 ; 0.8,0.8)$ \\
Very Strong (VS) & $(5,6,8,9 ; 1,1)$, \\
& $(5.2,6.2,7.8,8.8 ; 0.8,0.8)$ \\
Fairly Strong (FS) & $(3,4,6,7 ; 1,1)$ \\
& $(3.2,4.2,5.8,6.8 ; 0.8,0.8)$ \\
Slightly Strong (SS) & $(1,2,4,5 ; 1,1)$, \\
& $(1.2,2.2,3.8,4.8 ; 0.8,0.8)$ \\
Exactly Equal (E) & $(1,1,1,1 ; 1,1)$, \\
& $(1,1,1,1 ; 1,1)$ \\
If factor $i$ has one of the above & Reciprocals of above \\
linguistic variables assigned to it & \\
when compared with factor j, then $\mathrm{j}$ & \\
has the reciprocal value when & \\
compared with $i$. &
\end{tabular}

As a result, a sample comparison matrix that integrates interval type-2 fuzzy sets $(\widetilde{\widetilde{A}})$ is formed as given in the following;

$$
\widetilde{\widetilde{A}}=\left[\begin{array}{cccc}
1 & \widetilde{\widetilde{a}}_{12} & \cdots & \widetilde{\widetilde{a}}_{1 n} \\
1 / \widetilde{\widetilde{a}}_{12} & 1 & \cdots & \widetilde{\widetilde{a}}_{2 n} \\
\vdots & \vdots & \ddots & \vdots \\
1 / \widetilde{\widetilde{a}}_{1 n} & 1 / \widetilde{\widetilde{a}}_{2 n} & \cdots & 1
\end{array}\right]
$$

where

$$
\begin{aligned}
& \tilde{\tilde{a}} \\
& =\left(\left(a_{11}^{U}, a_{12}^{U}, a_{13}^{U}, a_{14}^{U} ; H_{1}\left(a_{12}^{U}\right), H_{2}\left(a_{13}^{U}\right)\right),\right. \\
& \left.\left(a_{21}^{L}, a_{22}^{L}, a_{23}^{L}, a_{24}^{L} ; H_{1}\left(a_{22}^{L}\right), H_{2}\left(a_{23}^{L}\right)\right)\right)
\end{aligned}
$$

and

$$
\begin{aligned}
& 1 / \tilde{\tilde{a}} \\
& =\left(\left(\frac{1}{a_{14}^{U}}, \frac{1}{a_{13}^{U}}, \frac{1}{a_{12}^{U}}, \frac{1}{a_{11}^{U}} ; H_{1}\left(a_{12}^{U}\right), H_{2}\left(a_{13}^{U}\right)\right),\right. \\
& \left.\left(\frac{1}{a_{24}^{L}}, \frac{1}{a_{23}^{L}}, \frac{1}{a_{22}^{L}}, \frac{1}{a_{21}^{L}} ; H_{1}\left(a_{22}^{L}\right), H_{2}\left(a_{23}^{L}\right)\right)\right)
\end{aligned}
$$

Step 3: Examining the consistency of the fuzzy pairwise comparison matrices. To this end, the comparison matrix is defuzzified and checked for consistency. If any inconsistency is detected, then the matrix is formed again.

Step 4: Aggregating the expert evaluations using geometric mean.

where

$$
\begin{aligned}
& \sqrt[n]{\tilde{\tilde{a}}_{i j}}=\left(\left(\sqrt[n]{a_{i j 1}^{U}}, \sqrt[n]{a_{i j 2}^{U}}, \sqrt[n]{a_{i j 3}^{U}}, \sqrt[n]{a_{i j 4}^{U}} ; H_{1}^{u}\left(a_{i j}\right), H_{2}^{u}\left(a_{i j}\right)\right),\right. \\
& \left.\left(\sqrt[n]{a_{i j 1}^{L}}, \sqrt[n]{a_{i j 2}^{L}}, \sqrt[n]{a_{i j 3}^{L}}, \sqrt[n]{a_{i j 4}^{L}} ; H_{1}^{L}\left(a_{i j}\right), H_{2}^{L}\left(a a_{i j}\right)\right)\right)
\end{aligned}
$$

Step 5: Calculating the fuzzy weights for each criterion in a comparison matrix. To this end primarily the geometric mean of each row $\left(\widetilde{\widetilde{r}}_{i}\right)$ is calculated using Equations 24 and 25;

Then fuzzy weight of the $i^{\text {th }}$ criterion $\left(\tilde{\tilde{p}}_{i}\right)$ is calculated using Equation 26.

$\tilde{\tilde{p}}_{i}=\tilde{\tilde{r}}_{i} \otimes\left[\tilde{\tilde{r}}_{1} \oplus \ldots \oplus \tilde{\tilde{r}}_{i} \oplus \ldots \oplus \tilde{\tilde{r}}_{n}\right]^{-1}$

The fuzzy weight calculated as a result of a pairwise comparison matrix is called the local weights, in order to find the global weights of each sub-criteria, the local weights should be multiplied by the local weight of the upper level criteria.

Step 6: Defuzzifying fuzzy weights to determine the importance of weights. The DTtrT method ([75]) is used for defuzzification in this step.

$D T \operatorname{tr} T=$

$\frac{\frac{\left(u_{U}-l_{U}\right)+\left(\beta_{U} \cdot m_{1}-l_{U}\right)+\left(\alpha_{U} \cdot m_{2 U}-l_{U}\right)}{4}+l_{U}+\left[\frac{\left(u_{L}-l_{L}\right)+\left(\beta_{L} \cdot m_{1 L}-l_{L}\right)+\left(\alpha_{L} \cdot m_{2 L}-l_{L}\right)}{4}+l_{L}\right]}{2}$

In the classical flow of AHP, scores for each alternative is also determined in a similar way. However in this study, since the alternative evaluations are done by HFS TOPSIS, only weights of the criteria are determined.

\subsection{Hesitant Fuzzy TOPSIS}

The TOPSIS (technique for order preference by similarity to an ideal solution), originally developed by Huang and Yoon [78], is a multi criteria decision making method which evaluates the alternatives according to their distances to the optimal solution. In the initial step, the positive and negative ideal solutions are determined. The positive ideal solution $(\mathrm{A}+)$ is obtained by selecting the largest normalized and weighted score for each criterion. In a similar way, the negative ideal solution (A-) is determined by selecting the least normalized and weighted score of each criterion [79]. Then, for each alternative, the distances to the positive and negative ideal solution are calculated and these values are later used to calculate the closeness index. Finally, the alternative with the highest index value is the selected as the best alternative. 
In the literature TOPSIS method has been largely extended by fuzzy sets. The importance of fuzzy TOPSIS is to assign the weights of attributes and the performance of alternatives by using fuzzy numbers instead of crisp numbers. Initially, Chen and Hwang [80] propose extending TOPSIS method with fuzzy sets. Later, Liang [81] presents a fuzzy multi-criteria decision-making based on the concepts of ideal and anti-ideal points using fuzzy set theory and hierarchical structure analysis to evaluate the alternatives from different criteria. Chen [82] extends fuzzy TOPSIS to group decision making field.

While various studies that focus on HFS exist in the literature ([47];[83];[84]), TOPSIS technique is also extended to operate with HFS. Recently, Xu and Zhang [67], propose an approach integrated with TOPSIS to be used in situations where the weight information is not complete and apply it to energy policy selection problem. Zhang and Wei [69] proposed using VIKOR with HFS and compared the results with HFS-VIKOR and applied to group decision making for project selection. Beg and Rashid [85] propose a new method to aggregate experts' opinions where the opinions are represented as HFLTS and apply it on investment selection problem. Liu and Rodriguez [45] propose a representation of the HFLTSs by means of a fuzzy envelope and use it in a case study using TOPSIS. Based on these studies, the steps of TOPSIS to be used in this paper are as follows:

Step 1: the positive and negative ideal solutions are determined

$A^{*}=\left\{h_{1}^{*}, h_{2}^{*}, \ldots . h_{n}^{*}\right\}$

where

$h_{j}^{*}=\cup_{i=1}^{m} h_{i j}=$

$\cup_{\gamma_{1 j} \in h_{1 j}, \ldots . ., \gamma_{m j} \in h_{m j}}, \max \left\{\gamma_{1 j}, \ldots . \gamma_{m j}\right\} j=1,2, \ldots, n$

$A^{-}=\left\{h_{1}^{-}, h_{2}^{-}, \ldots . h_{n}^{-}\right\}$;

where

$h_{j}^{*}=\cap_{i=1}^{m} h_{i j}=$

$\cap_{\gamma_{1 j} \in h_{1 j}, \ldots ., \gamma_{m j} \in h_{m j}}, \min \left\{\gamma_{1 j}, \ldots . . \gamma_{m j}\right\} j=1,2, \ldots, n$

Step 2: Separation measures of each alternative from the ideal solution is calculated. In this study, weighted hesitant normalized Hamming distance is used as a separation measure. The distance of an alternative form positive ideal is calculated as follows:

$D_{i}^{+}=\sum_{j=1}^{n} w_{j}\left\|h_{i j}-h_{j}^{*}\right\|$

where $w_{j}$ represents the weight of the $j$ th criterion determined by interval type-2 fuzzy AHP.

Similarly, the separation from the negative ideal solution is given as

$D_{i}^{-}=\sum_{j=1}^{n} w_{j}\left\|h_{i j}-h_{j}^{-}\right\|$

The distance between two hesitant fuzzy numbers is determined by using Eq. 32 . $\left\|h_{1}-h_{2}\right\|=\frac{1}{l} \sum_{j=1}^{l}\left|h_{1 \sigma(j)}-h_{2 \sigma(j)}\right|$

Step 3: Relative closeness to the ideal solution is calculated using the following equation:

$C_{i}=\frac{D_{i}^{-}}{D_{i}^{-}+D_{i}^{+}}$

Step 4: The alternatives are ranked according relative closeness; the alternative with the highest value is selected as the best alternative.

Briefly, the steps of the proposed methodology are given in Figure 3.

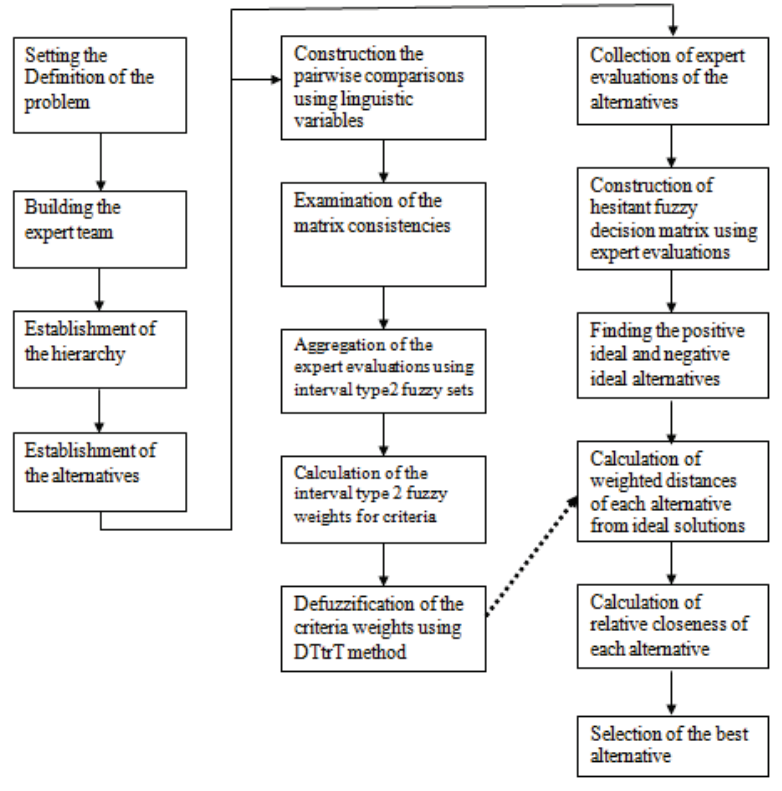

Figure 3: Flow chart of the proposed methodology

\section{A Real Case Study}

A leading commercial electronics company wants to make an investment on a new technological area and a partner company is available. In principle the partnership seems mutual beneficial to both of the parties since both of the companies have different competencies. The main problem is to select the form of governance for the partnership. Different managers are involved in the decision making process and all have different perspectives. There are mainly four decision makers whom are the managers of the company. All the decision makers reflect different perspectives namely human resource, operations, marketing and finance perspectives and consequently. Therefore a model that considers different perspectives into account with an analytical point of view will increase the performance of strategic decision making. 


\subsection{Determination of the criteria weights}

The importance weights of the decision criteria are determined using interval type-2 AHP. In this manner first pairwise comparison matrices are formed using experts' linguistic evaluations. Later all matrices are put through consistency check and found to be consistent. Table 5 represents experts' linguistic evaluations of main criteria with respect to their importance on the goal.

Table 5: Expert Evaluations of main criteria with respect to the goal

\begin{tabular}{|c|c|c|c|c|c|c|c|c|c|c|c|c|c|c|c|c|}
\hline & & & C1 & & & & C2 & & & C3 & & & & C4 & & \\
\hline & E1 & E2 & E3 & E4 & E1 & E2 & E3 & E4 & E1 & E2 & E3 & E4 & E1 & E2 & E3 & E4 \\
\hline $\mathrm{C} 1$ & E & E & E & E & $1 / \mathrm{FS}$ & FS & E & SS & $1 / \mathrm{FS}$ & $1 / \mathrm{FS}$ & VS & FS & $1 / \mathrm{FS}$ & $1 / \mathrm{VS}$ & E & E \\
\hline $\mathrm{C} 2$ & FS & $1 / \mathrm{FS}$ & E & $1 / \mathrm{SS}$ & E & $\mathrm{E}$ & E & E & $1 / \mathrm{FS}$ & $1 / \mathrm{VS}$ & VS & SS & SS & $1 / \mathrm{SS}$ & $1 / \mathrm{FS}$ & VS \\
\hline $\mathrm{C} 3$ & FS & FS & $1 / \mathrm{VS}$ & $1 / \mathrm{FS}$ & FS & VS & $1 / \mathrm{VS}$ & $1 / \mathrm{SS}$ & E & E & E & E & $1 / \mathrm{SS}$ & AS & $1 / \mathrm{SS}$ & VS \\
\hline $\mathrm{C} 4$ & FS & VS & E & E & $1 / \mathrm{SS}$ & SS & FS & $1 / \mathrm{VS}$ & SS & $1 / \mathrm{AS}$ & SS & $1 / \mathrm{VS}$ & E & E & E & E \\
\hline
\end{tabular}

An example of the pair wise comparisons between $\mathrm{C} 1$ and $\mathrm{C} 2$ is given in the following. For the calculation of the aggregated comparison value of four experts, first the linguistic evaluations (1/FS,FS,E,SS) are transformed to related interval type-2 fuzzy sets $(0.14,0.16,0.25,0.33 ; 1,1),(0.14,0.17,0.23,0.31 ; 0.8,0.8)$; $(3,4,6,7 ; \quad 1,1),(3.2,4.2,5.8,6.8 ; 0.8,0.8) ; \quad(1,1,1,1 ; 1,1)$, $(1,1,1,1 ; 1,1) ;(1,2,4,5 ; 1,1),(1.2,2.2,3.8,4.8 ; 0.8,0.8)$.

Using Eq.24 the aggregated evaluation is calculated: $\tilde{\tilde{a}}_{12}$

$=[(0.14,0.16,0.25,0.33 ; 1,1),(0.14,0.17,0.23,0.31 ; 0.8,0.8)$

$\otimes(3,4,6,7 ; 1,1),(3.2,4.2,5.8,6.8 ; 0.8,0.8)$

$\otimes(1,1,1,1 ; 1,1),(1,1,1,1 ; 1,1)$

$\otimes(1,2,4,5 ; 1,1),(1.2,2.2,3.8,4.8 ; 0.8,0.8)]^{1 / 4}$

$=(0.80,1.07,1.56,1.84 ; 1,1),(0.86,1.12,1.51,1.78 ; 0.8,0.8)$

The aggregated values for expert evaluations are given in Table 6.

Table 6: Aggregated expert evaluations of criteria with respect to goal.

\begin{tabular}{ccccc}
\hline \multicolumn{5}{c}{ Table 6: Aggregated expert evaluations of criteria with respect to goal. } \\
\hline C1 & $(1,1,1,1 ; 1,1)$, & $(0.80,1.07,1.56,1.84 ; 1,1)$, & $(0.74,0.90,1.31,1.62 ; 1,1)$, & $(0.35,0.37,0.45,0.50 ; 1,1)$, \\
& $(1,1,1,1 ; 1,1)$ & $(0.86,1.12,1.51,1.78 ; 0.8,0.8)$ & $(0.77,0.93,1.26,1.55 ; 0.8,0.8)$ & $(0.35,0.38,0.44,0.49 ; 0.8,0.8)$ \\
C2 & $(0.54,0.63,0.93,1.23 ; 1,1)$, & $(1,1,1,1 ; 1,1)$, & $(0.53,0.70,1.07,1.31 ; 1,1)$, & $(0.61,0.84,1.41,1.96 ; 1,1)$, \\
& $(0.55,0.66,0.89,1.15 ; 0.8,0.8)$ & $(1,1,1,1 ; 1,1)$ & $(0.56,0.74,1.03,1.26 ; 0.8,0.8)$ & $(0.66,0.88,1.33,1.82 ; 0.8,0.8)$ \\
C3 & $(0.61,0.75,1.10,1.34 ; 1,1)$, & $(0.75,0.93,1.41,1.88 ; 1,1)$, & $(1,1,1,1 ; 1,1)$, & $(1.08,1.31,2.05,3 ; 1,1)$, \\
& $(0.64,0.79,1.06,1.29 ; 0.8,0.8)$ & $(0.79,0.96,1.34,1.75 ; 0.8,0.8)$ & $(1,1,1,1 ; 1,1)$ & $(1.12,1.36,1.94,2.71 ; 0.8,0.8)$ \\
C4 & $(1.96,2.21,2.63,2.81 ; 1,1)$, & $(0.50,0.70,1.18,1.62 ; 1,1)$, & $(0.33,0.48,0.75,0.91 ; 1,1)$, & $(1,1,1,1 ; 1,1)$, \\
& $(2.01,2.25,2.59,2.78 ; 0.8,0.8)$ & $(0.54,0.74,1.12,1.51 ; 0.8,0.8)$ & $(0.36,0.51,0.73,0.88 ; 0.8,0.8)$ & $(1,1,1,1 ; 1,1)$ \\
\hline
\end{tabular}

Using the values in Table 6, geometric means of each row is calculated. For example for the first row $\left(\widetilde{\widetilde{r}}_{i}\right)$ is calculated as:

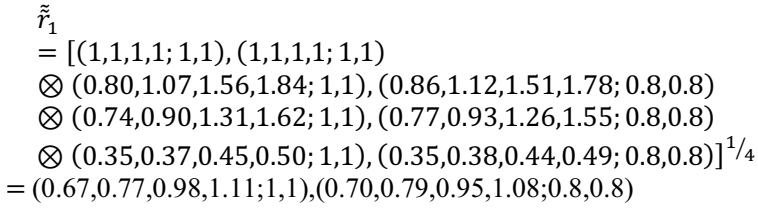

The values for all rows are listed as follows:

Table 7: Geometric means of each row

\begin{tabular}{ll} 
& Fuzzy Geometric Means \\
\hline$\tilde{\tilde{r}}_{1}$ & $(0.67,0.77,0.98,1.11 ; 1,1),(0.70,0.79,0.95,1.08 ; 0.8,0.8)$ \\
$\tilde{\tilde{r}}_{2}$ & $(0.64,0.78,1.09,1.33 ; 1,1),(0.67,0.81,1.05,1.27 ; 0.8,0.8)$ \\
$\tilde{\tilde{r}}_{3}$ & $(0.84,0.98,1.33,1.66 ; 1,1),(0.87,1.01,1.29,1.57 ; 0.8,0.8)$ \\
$\tilde{\tilde{r}}_{4}$ & $(0.75,0.93,1.24,1.43 ; 1,1),(0.79,0.96,1.20,1.38 ; 0.8,0.8)$ \\
\hline
\end{tabular}

Next the weight of each criteria is determined using Eq.26. For criterion $1(\mathrm{C} 1)$ the operations are given in the following:

$$
\begin{aligned}
& \tilde{\tilde{p}}_{1} \\
& =(0.67,0.77,0.98,1.11 ; 1,1),(0.70,0.79,0.95,1.08 ; 0.8,0.8) \\
& \otimes[(0.67,0.77,0.98,1.11 ; 1,1),(0.70,0.79,0.95,1.08 ; 0.8,0.8) \\
& \oplus(0.64,0.78,1.09,1.33 ; 1,1),(0.67,0.81,1.05,1.27 ; 0.8,0.8) \\
& \bigoplus(0.84,0.98,1.33,1.66 ; 1,1),(0.87,1.01,1.29,1.57 ; 0.8,0.8) \\
& \bigoplus(0.75,0.93,1.24,1.43 ; 1,1),(0.79,0.96,1.20,1.38 ; 0.8,0.8)]^{-1} \\
& =(0.67,0.77,0.98,1.11 ; 1,1),(0.70,0.79,0.95,1.08 ; 0.8,0.8) \\
& \otimes[(2.93,3.48,4.65,5.54 ; 1,1),(3.04,3.58,4.51,5.32 ; 0.8,0.8)]^{-1} \\
& =(0.67,0.77,0.98,1.11 ; 1,1),(0.70,0.79,0.95,1.08 ; 0.8,0.8) \otimes \\
& \quad(0.18,0.21,0.28,0.34 ; 1,1),(0.18,0.22,0.27,0.32 ; 0.8,0.8) \\
& =(0.12,0.16,0.28,0.37 ; 1,1),(0.13,0.17,0.26,0.35 ; 0.8,0.8)
\end{aligned}
$$

Finally the defuzzified values are determined using Eq. 27.

$$
\begin{aligned}
& W_{1} \\
& =\frac{\left[\frac{(0.25)+(0.04)+(0.16)}{4}+0.12\right]}{2} \\
& +\frac{\left[\frac{(0.223)+(0.8 \times 0.17-0.13)+(0.8 \times 0.26-0.13)}{4}+0.13\right]}{2} \\
& =0.224
\end{aligned}
$$


The fuzzy, crisp and normalized weights of the criteria are given in Table 8. It is important to note that for the rest of the operations fuzzy weights are used.
Using the same steps importance weights of subcriteria are determined. Tables 9-12 represent the expert evaluations of the subcriteria with respect to the related criteria.

\begin{tabular}{cccc}
\multicolumn{5}{c}{ Table 8: Fuzzy and Normalized weights of the criteria } \\
\hline Criteria & Fuzzy Weights & $\begin{array}{c}\text { Crisp } \\
\text { Weights }\end{array}$ & $\begin{array}{c}\text { Normalized } \\
\text { Crisp Weights }\end{array}$ \\
\hline C1 & $(0.12,0.16,0.28,0.37 ; 1,1),(0.13,0.17,0.26,0.35 ; 0.8,0.8)$ & 0.224 & 0.212 \\
C2 & $(0.11,0.16,0.31,0.45 ; 1,1),(0.12,0.17,0.29,0.41 ; 0.8,0.8)$ & 0.247 & 0.234 \\
C3 & $(0.15,0.21,0.38,0.56 ; 1,1),(0.16,0.22,0.36,0.51 ; 0.8,0.8)$ & 0.308 & 0.291 \\
C4 & $(0.13,0.20,0.35,0.48 ; 1,1),(0.15,0.21,0.33,0.45 ; 0.8,0.8)$ & 0.279 & 0.263 \\
\hline
\end{tabular}

Table 9: Expert Evaluations of sub-criteria (C11-C13) with respect to Environmental Factors

\begin{tabular}{|c|c|c|c|c|c|c|c|c|c|c|c|c|}
\hline & & $\begin{array}{r}\mathrm{C} \\
\text { Exp2 } \\
\end{array}$ & 11 & & & $\mathrm{C}$ & 12 & & & $\begin{array}{r}\mathrm{C} 1 \\
\mathrm{p} 2 \\
\end{array}$ & $\begin{array}{l}13 \\
\text { Exp3 }\end{array}$ & $\mathbf{E x p}$ \\
\hline & E & E & E & E & W & & $1 / \mathrm{FS}$ & W & S & $1 / \mathrm{VS}$ & $1 / \mathrm{A}$ & $\mathrm{E}$ \\
\hline 2 & $1 / \mathrm{W}$ & $1 / \mathrm{E}$ & & $1 /$ & $F$ & E & E & $F$ & $1 / \mathrm{W}$ & $1 / \mathrm{FS}$ & $1 / \mathrm{A}$ & $1 / \mathrm{W}$ \\
\hline$|3|$ & $/ F S$ & VS & A & $1 / \mathrm{E}$ & W & $\mathrm{FS}$ & $\Lambda$ & W & $\mathrm{E}$ & E & 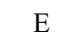 & E \\
\hline
\end{tabular}

Table 10: Expert Evaluations of sub-criteria (C21-C25) with respect to Firm Related Factors

\begin{tabular}{|c|c|c|c|c|c|c|c|c|c|c|c|c|c|c|c|c|c|c|c|c|}
\hline & \multicolumn{4}{|c|}{ C21 } & \multicolumn{4}{|c|}{$\mathrm{C} 22$} & \multicolumn{4}{|c|}{$\mathrm{C} 23$} & \multicolumn{4}{|c|}{$\mathrm{C24}$} & \multicolumn{4}{|c|}{$\mathrm{C} 25$} \\
\hline & Exp1 & Exp2 & Exp3 & Exp4 & Exp1 & Exp2 & Exp3 & Exp4 & Exp1 & Exp2 & Exp3 & Exp4 & Exp1 & Exp2 & Exp3 & Exp4 & Exp1 & Exp2 & Exp3 & Exp4 \\
\hline C21 & E & E & E & E & VS & $1 / \mathrm{FS}$ & VS & W & W & $1 / \mathrm{VS}$ & E & FS & W & VS & E & E & E & $1 / \mathrm{VS}$ & W & W \\
\hline $\mathrm{C} 22$ & $1 / \mathrm{VS}$ & FS & $1 / \mathrm{VS}$ & $1 / \mathrm{W}$ & $\mathrm{E}$ & $\mathrm{E}$ & $\mathrm{E}$ & E & W & FS & $1 / \mathrm{VS}$ & FS & $1 / \mathrm{FS}$ & $1 / \mathrm{A}$ & $1 / \mathrm{FS}$ & E & $1 / \mathrm{W}$ & $1 / \mathrm{FS}$ & $1 / \mathrm{A}$ & W \\
\hline $\mathrm{C} 23$ & $1 / \mathrm{W}$ & VS & $1 / \mathrm{E}$ & $1 / \mathrm{FS}$ & $1 / \mathrm{W}$ & 1/FS & VS & $1 / \mathrm{FS}$ & E & E & E & E & E & $1 / \mathrm{W}$ & W & VS & W & 1/FS & E & $\mathrm{E}$ \\
\hline $\mathrm{C} 24$ & $1 / \mathrm{W}$ & $1 / \mathrm{VS}$ & $1 / \mathrm{E}$ & $1 / \mathrm{E}$ & FS & A & FS & $1 / \mathrm{E}$ & $1 / \mathrm{E}$ & W & $1 / \mathrm{W}$ & $1 / \mathrm{VS}$ & E & E & $\mathrm{E}$ & E & $1 / \mathrm{FS}$ & $1 / \mathrm{VS}$ & $1 / \mathrm{W}$ & FS \\
\hline $\mathrm{C} 25$ & $1 / \mathrm{E}$ & VS & $1 / \mathrm{W}$ & $1 / \mathrm{W}$ & W & FS & A & $1 / \mathrm{W}$ & $1 / \mathrm{W}$ & FS & $1 / \mathrm{E}$ & $1 / \mathrm{E}$ & FS & VS & W & $1 / \mathrm{FS}$ & E & E & E & E \\
\hline
\end{tabular}

Table 11: Expert Evaluations of sub-criteria (C31-C35) with respect to Partner Firm Related Factors

\begin{tabular}{|c|c|c|c|c|c|c|c|c|c|c|c|c|c|c|c|c|c|c|c|c|}
\hline & Exp1 & $\begin{array}{r}\mathrm{C} \\
\text { Exp2 } \\
\end{array}$ & & & Exp1 & $\begin{array}{r}\mathrm{C} \\
\text { Exp2 } \\
\end{array}$ & $\begin{array}{l}32 \\
\text { Exp3 }\end{array}$ & & & & $\begin{array}{l}33 \\
\text { Exp3 }\end{array}$ & Exp4 & Exp1 & & $\begin{array}{l}34 \\
\text { Exp3 } \\
\end{array}$ & & Exp1 & $\begin{array}{r}\mathrm{C} \\
\text { Exp2 } \\
\end{array}$ & $\begin{array}{l}35 \\
\text { Exp3 }\end{array}$ & Exp4 \\
\hline C31 & E & E & E & E & $1 / \mathrm{FS}$ & VS & $1 / \mathrm{FS}$ & FS & 1/FS & VS & $1 / \mathrm{FS}$ & W & $1 / \mathrm{W}$ & $1 / \mathrm{FS}$ & VS & $\mathrm{E}$ & $1 / \mathrm{W}$ & $1 / \mathrm{FS}$ & FS & W \\
\hline C32 & FS & $1 / \mathrm{VS}$ & FS & $1 / \mathrm{FS}$ & E & E & E & E & $\mathrm{E}$ & FS & W & FS & W & VS & VS & $1 / \mathrm{W}$ & E & $1 / \mathrm{VS}$ & VS & $1 / \mathrm{FS}$ \\
\hline C33 & FS & $1 / \mathrm{VS}$ & FS & $1 / \mathrm{W}$ & $1 / \mathrm{E}$ & $1 / \mathrm{FS}$ & $1 / \mathrm{W}$ & $1 / \mathrm{FS}$ & E & E & E & E & $1 / \mathrm{W}$ & $1 / \mathrm{FS}$ & FS & $1 / \mathrm{W}$ & 1/FS & $1 / \mathrm{FS}$ & $1 / \mathrm{VS}$ & W \\
\hline C34 & W & FS & $1 / \mathrm{VS}$ & $1 / \mathrm{E}$ & $1 / \mathrm{W}$ & $1 / \mathrm{VS}$ & $1 / \mathrm{VS}$ & W & W & FS & $1 / \mathrm{FS}$ & W & $\mathrm{E}$ & $\mathrm{E}$ & E & E & $1 / \mathrm{W}$ & $1 / \mathrm{VS}$ & $1 / \mathrm{A}$ & FS \\
\hline $\mathrm{C} 35$ & W & FS & $1 / \mathrm{FS}$ & $1 / \mathrm{W}$ & $1 / \mathrm{E}$ & VS & $1 / \mathrm{VS}$ & FS & FS & FS & VS & $1 / \mathrm{W}$ & W & VS & A & $1 / \mathrm{FS}$ & E & E & E & E \\
\hline
\end{tabular}


Table 12: Expert Evaluations of sub-criteria (C41-C44) with respect to Decision related factors

\begin{tabular}{|c|c|c|c|c|c|c|c|c|c|c|c|c|c|c|c|c|}
\hline & Exp1 & $\begin{array}{r}\mathrm{C} \\
\operatorname{Exp} 2 \\
\end{array}$ & $\begin{array}{l}41 \\
\text { Exp3 }\end{array}$ & Exp4 & Exp1 & $\begin{array}{r}\mathrm{C} \\
\text { Exp2 } \\
\end{array}$ & $\begin{array}{l}42 \\
\text { Exp3 }\end{array}$ & Exp4 & Exp1 & $\begin{array}{r}\mathrm{C} \\
\text { Exp2 } \\
\end{array}$ & $\begin{array}{l}43 \\
\text { Exp3 }\end{array}$ & Exp4 & Exp1 & $\begin{array}{r}\mathrm{C} \\
\text { Exp2 } \\
\end{array}$ & $\begin{array}{l}44 \\
\text { Exp3 }\end{array}$ & Exp4 \\
\hline C41 & E & $\mathrm{E}$ & $\mathrm{E}$ & E & FS & $1 / \mathrm{FS}$ & FS & E & 1/FS & 1/VS & VS & W & W & FS & VS & VS \\
\hline C42 & $1 / \mathrm{FS}$ & FS & $1 / \mathrm{FS}$ & $1 / \mathrm{E}$ & E & E & $\mathrm{E}$ & E & $\mathrm{E}$ & W & VS & W & $1 / \mathrm{FS}$ & $1 / \mathrm{W}$ & $1 / \mathrm{FS}$ & FS \\
\hline $\mathrm{C43}$ & FS & VS & $1 / \mathrm{VS}$ & $1 / \mathrm{W}$ & $1 / \mathrm{E}$ & $1 / \mathrm{W}$ & 1/VS & $1 / \mathrm{W}$ & E & E & $\mathrm{E}$ & E & W & VS & A & W \\
\hline C44 & $1 / \mathrm{W}$ & $1 / \mathrm{FS}$ & 1/VS & $1 / \mathrm{VS}$ & FS & W & FS & $1 / \mathrm{FS}$ & $1 / \mathrm{W}$ & 1/VS & $1 / \mathrm{A}$ & $1 / \mathrm{W}$ & E & E & E & E \\
\hline
\end{tabular}

Table 13: Local and global weights of the subcriteria.

\begin{tabular}{lll}
\hline Criteria & \multicolumn{1}{c}{ Local Weights } & \multicolumn{1}{c}{ Global Weights } \\
\hline C11 & $(0.14,0.19,0.30,0.40 ; 1,1),(0.15,0.20,0.29,0.38 ; 0.8,0.8)$ & $(0.018,0.032,0.087,0.15 ; 1,1),(0.020,0.036,0.078,0.13 ; 0.8,0.8)$ \\
C12 & $(0.10,0.13,0.22,0.35 ; 1,1),(0.10,0.13,0.21,0.31 ; 0.8,0.8)$ & $(0.012,0.02,0.063,0.13 ; 1,1),(0.014,0.02,0.056,0.11 ; 0.8,0.8)$ \\
C13 & $(0.33,0.46,0.73,0.94 ; 1,1),(0.36,0.48,0.69,0.89 ; 0.8,0.8)$ & $(0.041,0.077,0.20,0.35 ; 1,1),(0.047,0.085,0.18,0.31 ; 0.8,0.8)$ \\
C21 & $(0.13,0.20,0.36,0.49 ; 1,1),(0.14,0.21,0.34,0.45 ; 0.8,0.8)$ & $(0.015,0.034,0.11,0.22 ; 1,1),(0.018,0.038,0.10,0.19 ; 0.8,0.8)$ \\
C22 & $(0.05,0.084,0.15,0.22 ; 1,1),(0.064,0.090,0.14,0.20 ; 0.8,0.8)$ & $(0.006,0.014,0.048,0.10 ; 1,1),(0.008,0.016,0.042,0.087 ; 0.8,0.8)$ \\
C23 & $(0.092,0.13,0.23,0.34 ; 1,1),(0.10,0.13,0.22,0.31 ; 0.8,0.8)$ & $(0.010,0.021,0.074,0.15 ; 1,1),(0.01,0.024,0.065,0.13 ; 0.8,0.8)$ \\
C24 & $(0.091,0.12,0.22,0.32 ; 1,1),(0.098,0.13,0.20,0.29 ; 0.8,0.8)$ & $(0.010,0.021,0.06,0.14 ; 1,1),(0.012,0.023,0.061,0.12 ; 0.8,0.8)$ \\
C25 & $(0.13,0.19,0.37,0.55 ; 1,1),(0.14,0.21,0.34,0.50 ; 0.8,0.8)$ & $(0.016,0.033,0.11,0.25 ; 1,1),(0.019,0.038,0.10,0.20 ; 0.8,0.8)$ \\
C31 & $(0.089,0.13,0.25,0.38 ; 1,1),(0.097,0.14,0.23,0.35 ; 0.8,0.8)$ & $(0.013,0.027,0.098,0.21 ; 1,1),(0.015,0.03,0.086,0.18 ; 0.8,0.8)$ \\
C32 & $(0.12,0.18,0.35,0.49 ; 1,1),(0.13,0.20,0.32,0.46 ; 0.8,0.8)$ & $(0.019,0.039,0.13,0.28 ; 1,1),(0.022,0.044,0.11,0.23 ; 0.8,0.8)$ \\
C33 & $(0.055,0.080,0.16,0.25 ; 1,1),(0.060,0.085,0.14,0.22 ; 0.8,0.8)$ & $(0.008,0.016,0.061,0.14 ; 1,1),(0.009,0.019,0.053,0.11 ; 0.8,0.8)$ \\
C34 & $(0.069,0.10,0.21,0.31 ; 1,1),(0.076,0.11,0.19,0.28 ; 0.8,0.8)$ & $(0.010,0.022,0.080,0.17 ; 1,1),(0.012,0.025,0.070,0.14 ; 0.8,0.8)$ \\
C35 & $(0.14,0.21,0.41,0.60 ; 1,1),(0.15,0.23,0.38,0.55 ; 0.8,0.8)$ & $(0.022,0.045,0.15,0.34 ; 1,1),(0.025,0.051,0.13,0.28 ; 0.8,0.8)$ \\
C41 & $(0.19,0.27,0.49,0.68 ; 1,1),(0.20,0.29,0.47,0.64 ; 0.8,0.8)$ & $(0.026,0.055,0.17,0.33 ; 1,1),(0.031,0.063,0.15,0.29 ; 0.8,0.8)$ \\
C42 & $(0.11,0.16,0.31,0.44 ; 1,1),(0.12,0.18,0.29,0.40 ; 0.8,0.8)$ & $(0.016,0.033,0.11,0.21 ; 1,1),(0.019,0.038,0.098,0.18 ; 0.8,0.8)$ \\
C43 & $(0.13,0.20,0.37,0.55 ; 1,1),(0.15,0.21,0.35,0.50 ; 0.8,0.8)$ & $(0.019,0.040,0.13,0.27 ; 1,1),(0.022,0.04,0.11,0.23 ; 0.8,0.8)$ \\
C44 & $(0.064,0.090,0.17,0.26 ; 1,1),(0.069,0.095,0.15,0.23 ; 0.8,0.8)$ & $(0.008,0.01,0.061,0.12 ; 1,1),(0.01,0.020,0.053,0.10 ; 0.8,0.8)$ \\
\hline
\end{tabular}

Using the steps given below, the weights of each sub criteria are determined. The weights of sub criteria with respect to the related criteria are entitled the local weights of the subcriteria. The weights of each subcriteria with respect to the goal is called global weight and calculated by multiplying the local weights with weight of the related criteria. The local and global weights of the subcriteria are represented in Table 13.

Using DTtrT method [75] for defuzzification, the crisp and normalized crisp weights of the subcriteria are determined as listed in Table 14.

The results imply that among the main criteria the most important one is partner focal firm related factors (0.291) which are followed by decision related factors (0.263). Firm related factors criterion has the importance weight of 0.234 and the least important factor is determined as environmental factors. When the weights of the subcriteria in Table 14 are investigated, environmental uncertainty has the highest importance weight $(0.11)$ followed by partner's similarity (0.09), partner's international experience $(0.08)$, partner's product variety $(0.07)$ and prior relations $(0.07)$.
Table 14: The defuzzified and normalized global weights of the subcriteria.

\begin{tabular}{lcc}
\hline Criteria & $\begin{array}{c}\text { Defuzzified } \\
\text { Weights }\end{array}$ & $\begin{array}{c}\text { Normalized } \\
\text { Weights }\end{array}$ \\
\hline C11 & 0.0676 & 0.0471 \\
C12 & 0.0531 & 0.0370 \\
C13 & 0.1582 & 0.1102 \\
C21 & 0.0889 & 0.0619 \\
C22 & 0.0398 & 0.0277 \\
C23 & 0.0605 & 0.0421 \\
C24 & 0.0564 & 0.0393 \\
C25 & 0.0946 & 0.0659 \\
C31 & 0.0814 & 0.0567 \\
C32 & 0.1085 & 0.0756 \\
C33 & 0.0522 & 0.0363 \\
C34 & 0.0659 & 0.0459 \\
C35 & 0.1291 & 0.0899 \\
C41 & 0.1369 & 0.0954 \\
C42 & 0.0867 & 0.0604 \\
C43 & 0.1064 & 0.0742 \\
C44 & 0.0493 & 0.0344 \\
\hline
\end{tabular}


The subcriteria with the lowest importance are determined as partner's product variety $(0.02)$ followed by, cultural distance between partners (0.03) and partner's international experience (0.03). These importance weights are directly used for distance measurement in the following section.

The results imply that among the main criteria the most important one is partner focal firm related factors (0.291) which are followed by decision related factors (0.263). Firm related factors criterion has the importance weight of 0.234 and the least important factor is determined as environmental factors. When the weights of the subcriteria in Table 14 are investigated, environmental uncertainty has the highest importance weight $(0.11)$ followed by partner's similarity (0.09), partner's international experience (0.08), partner's product variety $(0.07)$ and prior relations $(0.07)$. The subcriteria with the lowest importance are determined as partner's product variety $(0.02)$ followed by, cultural distance between partners (0.03) and partner's international experience (0.03). These importance weights are directly used for distance measurement in the following section.

\subsection{Evaluation of the Alternatives}

Afore mentioned decision makers with different perspectives anonymously evaluated four strategic decision alternatives according to the subcriteria. All the decisions makers scored each strategic decision with respect to the subcriteria and some of these scores are repeated. As $\mathrm{Xu}$ and Zhang [67] mentioned in their study the value that is repeated more than one time does not always indicate a higher importance. In this case since all the managers reflect different perspectives each one can have higher expertise on the different subcriterion therefore giving importance to the scores which are repeated more than one is not reasonable. HFS are good tools to deal with such cases since they allow us to collect possible scores for an alternative under a subcriterion. Table 15 shows these possible scores of each strategic decision under different subcriteria in which the scores repeated many times appear only once.

Table 15: Hesitant Fuzzy Decision Matrix

\begin{tabular}{|lllllll|}
\hline & C11 & C12 & C13 & C21 & C22 & C23 \\
\hline JV & $\{0.3,0.5,0.9\}$ & $\{0.1,0.3,0.7\}$ & $\{0.3,0.7,0.9\}$ & $\{0.1,0.3,0.9\}$ & $\{0.7,0.9\}$ & $\{0.1,0.5,0.7\}$ \\
M & $\{0.1,0.5,0.7\}$ & $\{0.1,0.3,0.7\}$ & $\{0.1,0.5\}$ & $\{0.1,0.3,0.5,0.7\}$ & $\{0.1,0.3,0.5\}$ & $\{0.1,0.3,0.7\}$ \\
A & $\{0.1,0.3,0.7\}$ & $\{0.1,0.3,0.9\}$ & $\{0.1,0.3\}$ & $\{0.1,0.3,0.9\}$ & $\{0.1,0.3,0.5\}$ & $\{0.1,0.3,0.9\}$ \\
NEA & $\{0.1,0.3\}$ & $\{0.1,0.5\}$ & $\{0.1,0.5\}$ & $\{0.1,0.3,0.5\}$ & $\{0.1\}$ & $\{0.1,0.3,0.9\}$ \\
\hline
\end{tabular}

\begin{tabular}{|lllllll|}
\hline & $\mathbf{C 2 4}$ & $\mathbf{C 2 5}$ & $\mathbf{C 3 1}$ & $\mathbf{C 3 2}$ & $\mathbf{C 3 3}$ & $\mathbf{C 3 4}$ \\
\hline JV & $\{0.1,0.5,0.9\}$ & $\{0.3,0.5,0.9\}$ & $\{0.1,0.5\}$ & $\{0.1,0.5,0.7\}$ & $\{0.7,0.9\}$ & $\{0.1,0.5,0.9\}$ \\
M & $\{0.1,0.3,0.5\}\{0.1,0.3,0.9\}$ & $\{0.1,0.3,0.7\}$ & $\{0.1,0.3,0.7,0.9\}$ & $\{0.1,0.3,0.5\}$ & $\{0.1,0.3,0.7,0.9\}$ \\
A & $\{0.1,0.5,0.9\}\{0.1,0.5,0.9\}$ & $\{0.1,0.3,0.5,0.7\}$ & $\{0.1,0.3,0.7,0.9\}$ & $\{0.1,0.7\}$ & $\{0.1,0.3,0.5\}$ \\
NEA & $\{0.1,0.3,0.7\}$ & $\{0.1,0.5\}$ & $\{0.1,0.3,0.5,0.9\}$ & $\{0.1,0.7\}$ & $\{0.1,0.7\}$ & $\{0.1,0.3\}$ \\
\hline
\end{tabular}

\begin{tabular}{|llllll|}
\hline & C35 & C41 & C42 & C43 & C44 \\
\hline JV & $\{0.5,0.7,0.9\}$ & $\{0.3,0.5,0.7,0.9\}$ & $\{0.3,0.5,0.9\}$ & $\{0.3,0.5,0.9\}$ & $\{0.9\}$ \\
M & $\{0.3,0.5\}$ & $\{0.1,0.5\}$ & $\{0.1,0.3\}$ & $\{0.1,0.3,0.5\}$ & $\{0.7,0.3\}$ \\
A & $\{0.3,0.5,0.7\}$ & $\{0.1,0.5,0.7\}$ & $\{0.1,0.5\}$ & $\{0.1,0.3,0.5\}$ & $\{0.70 .5,0.3\}$ \\
NEA & $\{0.1,0.3\}$ & $\{0.1,0.3\}$ & $\{0.1,0.5,0.7\}$ & $\{0.1,0.3\}$ & $\{0.1,0.3\}$ \\
\hline
\end{tabular}

At the first step of hesitant fuzzy TOPSIS, positive and negative ideal solutions are determined. To this end for each criterion, maximum and minimum membership values are found. For example for C11 is 0.9 and minimum value is 0.1 . Thus the $A^{*}$ and $A^{-}$values are obtained as given in the following.

$$
\begin{aligned}
& A^{*}=\left\{h_{1}^{*}, h_{2}^{*}, \ldots . h_{17}^{*}\right\} \\
& =\left\{\begin{array}{c}
0.90,0.90,0.90,0.90,0.90,0.90,0.90,0.90,0.90 \\
, 0.90,0.90,0.90,0.90,0.90,0.90,0.90,0.90
\end{array}\right\}
\end{aligned}
$$




$$
\begin{aligned}
& A^{-}=\left\{h_{1}^{-}, h_{2}^{-}, \ldots . h_{17}^{-}\right\} \\
& =\left\{\begin{array}{c}
0.10,0.10,0.10,0.10,0.10,0.10,0.10,0.10 \\
0.10,0.10,0.10,0.10,0.10,0.10,0.10,0.10,0.10
\end{array}\right\}
\end{aligned}
$$

Next, the separation measure of each alternative from ideal solution is calculated using Eq. 30

$$
\begin{aligned}
& D_{1}^{+}=0.0471 \times\|\{0.3,0.5,0.9\}-\{0.90\}\|+0.0370 \\
& \times\|\{0.1,0.3,0.7\}-\{0.90\}\|+\cdots+0.0344 \\
& \times\|\{0.90\}-\{0.90\}\|
\end{aligned}
$$

Hamming distance measure given in Eq. 32 is used to find the distance between two HFS. For the first distance value in the above formula is calculated as:

$$
\begin{aligned}
& d_{1}\left(h_{1}, h_{2}\right)=\frac{1}{l} \sum_{i=1}^{l}\left|h_{1_{\sigma(i)}}-h_{2_{\sigma(i)}}\right| \\
& \begin{aligned}
\|\{0.3,0.5,0.9\}-\{0.90\}\| & \\
& =\frac{1}{3}[|0.3-0.9|+|0.5-0.9|+|0.9-0.9|] \\
& =\frac{1}{3}[0.6+0.4+0]=0.333
\end{aligned}
\end{aligned}
$$

Using the same formula, both $D^{+}$and $D^{-}$are calculated and presented in Table 16. Finally the relative closeness values are calculated using Eq.33 for each alternative.

$$
C_{1}=\frac{D_{1}^{-}}{D_{1}^{-}+D_{1}^{+}}=\frac{0.537}{0.537+0.472}=0.532
$$

Table 16: Separation values and relative closeness of each alternative

\begin{tabular}{ccccc}
\hline Alternatives & D+ & D- & Ci & RANK \\
\hline JV & 0.472 & 0.537 & 0.532 & 1 \\
M & 0.442 & 0.338 & 0.433 & 3 \\
A & 0.434 & 0.368 & 0.458 & 2 \\
NEA & 0.394 & 0.263 & 0.401 & 4 \\
\hline
\end{tabular}

The relative closeness values of each alternative are represented in Table 16. The alternative with the highest value represents the best alternative among the others, thus, joint venture is the best alternative for this decision problem. Joint venture is followed by Acquisition and Merger. As implied in Table 16, nonequity alliance is the worst decision.

\section{Conclusions}

Our proposed method aims at helping managers in governance form selection problem where there are different decision makers and different alternatives such as; joint ventures, mergers, acquisition, and non equity alliance. The nature of the problem is complex and vague, involving different perspectives of different decision makers. The considered criteria are prioritized using interval type-2 fuzzy AHP which is developed by us and the alternatives are evaluated with respect to the criteria by using hesitant fuzzy TOPSIS.

In our application, the commercial electronics company and the partner firm are both from the same country and had good prior relations and wanted to establish a stronger relation therefore a non-equity alliance become the worst decision. Both of the firms are big firms with complex business structures, combining these structures will be very complicated and can cause diseconomy of scale. Consequently the joint venture becomes the best strategic decision for the company. The analytical model enables us to consider various uncertain and vague factors with different perspectives. The strategic decision makers can combine the results of the model with their intuitive decision making process and improve their decision making process.

We applied our proposed method to a real case problem in a commercial electronics company while the top level managers of this company prefer making their decision based on their traditional SWOT and Delphi type decision making system. While both our method and their traditional decision making system produced the same result, our method significantly reduced the decision making process.

For further research, AHP can be extended so as to work with HFS. Also another type of integration of multiattribute decision making methods can be proposed. This may be an integration of interval type- 2 fuzzy AHP and hesitant fuzzy VIKOR or an integration of interval type-2 fuzzy AHP and hesitant fuzzy ELECTRE. The obtained results from this new integrations can be compared by our results.

\section{References}

1 Ivan, M., and Ivana, B.: 'The Nature of Strategic Decision Making - Exploiting the role of managers' incremental and radical learning', The Journal of International Management Studies, 2012, 7, (2), pp. 7-19

2 Montibeller, G., and Franco, L.A.: 'Raising the bar: strategic multi-criteria decision analysis', Journal of the Operational Research Society, 2011, 62, (.), pp. 855-867

3 Schwenk, C.R.: 'The Essence of Strategic Decision Making' (Lexington Books,, 1988. 1988)

4 Ji, J., and Dimitratos, P.: 'An empirical investigation into international entry mode decision-making effectiveness', International Business Review, 2013, 22, (6), pp. 994 1007

5 Reuer, J., and Ragozzino, R.: 'The Choice Between Joint Ventures and Acquisitions: Insights from Signaling Theory', Organization Science, 2011, 23, (4), pp. 11751190 
6 Williamson, O.E.: 'Comparative economic organization: The analysis of discrete structural alternatives', Administrative Science Quarterly, 1991, 36, pp. 269-296

7 Zadeh, L.A.: 'Fuzzy sets', Information and Control 1965, 8, (3), pp. 338-353

8 Gulbay, M., Kahraman, C., and Ruan, D.: 'Alpha-cut fuzzy control charts for linguistic data', International Journal of Intelligent Systems, 2004, 19, (12), pp. 11731195

9 Irani, Z., Sharif, A., Love, P., and Kahraman, C.: 'Applying concepts of fuzzy cognitive mapping to model: The IT/IS investment evaluation process', International Journal of Production Economics, 2002, 75, (1-2), pp. 199-211

10 Tuysuz, F., and Kahraman, C.: 'Project risk evaluation using a fuzzy analytic hierarchy process: An application to information technology projects', International Journal of Intelligent Systems, 2006, 21, (6), pp. 559-584

11 Ekmekcioglu, M., Kaya, T., and Kahraman, C.: 'Fuzzy multicriteria disposal method and site selection for municipal solid waste', Waste Management 2010, 30, (89), pp. 1729-1736

12 Rodriguez, R.M., Martinez, L., and Herrera, F.: 'Hesitant Fuzzy Linguistic Term Sets for Decision Making', IEEE Transactions on Fuzzy Systems, 2012, 20, (1), pp. 109119

13 Torra, V.: 'Hesitant fuzzy sets', International Journal of Intelligent Systems, 2010, 25, pp. 529-539

14 Zadeh, L.A.: 'The concept of a linguistic variable and its application to approximate reasoning - I', Information Sciences, 1975, 8, (3), pp. 199-249

15 Kidd, J.: 'The networked management of strategic alliances: Oriental and Occidental perceptions', Computers \& Industrial Engineering, 2000, 38, pp. 203214

16 Hiller, N.J., and Hambrick, D.C.: 'Conceptualizing executive hubris: The role of (hyper-) core selfevaluations in strategic decision-making', Strategic Management Journal, 2005, 26, pp. 297- 319

17 Kıymaz, H., and Kılıç, O.: 'International Mergers and Acquisitions: A Jump Diffusion Model Application', Journal of Economics and Finance, 2004, 28, (3), pp. 239251

18 Elfakhani, S., Ghantous, R.F., and Baalbaki, I.: 'Megamergers in the US Banking Industry', Applied Financial Economics, 2003, 13, pp. 609-622

19 Jakobsen, J.B., and T., V.: 'Post-acquisition Performance in the Short and Long Run: Evidence from Copenhagen Stock Exchange 1993-1997', The European Journal of Finance, 2003, 9, pp. 323-342

20 Kiymaz, H., and Mukherjee, T.K.: 'Parameter Shifts When Measuring Wealth Effects in Cross-border Mergers', Global Finance Journal, 2001, 12, pp. 249-266

21 Zhang, A., and Aldridge, D.: 'Effects of Merger and Foreign Alliance: An Event Study At The Canadian Airline Industry', Transportation Res.-E, 1997, 33, (1), pp. 29-42

22 Walter, J., Kellermanns, F.W., and Lechner, C.: ' Decision making within and between organizations: Rationality, politics, and alliance performance', Journal of Management:, 2012, 38, (5), pp. 1582-1610
23 Wilcox, H.D., Chang, K.C., and Grover, V.: 'Valuation of Mergers and Acquisitions in the Telecommunications Industry: A Study on Diversification and Firm Size', Information and Management, 2001, 38, pp. 459-471

24 Yue, L., Sun, M., and Shao, Z.: 'The Probabilistic Hesitant Fuzzy Weighted Average Operators and Their Application in Strategic Decision Making', Journal of Information \& Computational Science, 2013, 10, (12), pp. 3841-3848

25 Hibbard, J.D., Hogan, J.E., and Smith, G.R.: 'Assessing the strategic value of business relationships: the value of uncertainty and flexibility', Journal of Business and Industrial Marketing, 2003, 18, (5), pp. 376-387

26 Brouthers, K.D., and Nakos, G.: 'SME Entry Mode Choice and Performance: A Transaction Cost Perspective', Entrepreneurship Theory and Practice, 2004, 28, (3), pp. 229-247

27 O'Brien, J.P., Folta, T., B., and Johnson, D.R.: ' A Real Options Perspective on Entrepreneural Entry in the Face of Uncertainty', Managerial and Decision Economics, 2003, 24, pp. 515-533

28 Reuer, J.J., and Leiblein, M.J.: 'Downside Risk Implications of Multinationality and International Joint Ventures', Academy of Management Journal, 2000, 43, pp. 203-214

29 Brouthers, K.D., Brouthers, L.E., and Werner, S.: 'Transaction cost-enhanced entry mode choices and firm performance', Strategic Management Journal, 2003, 24 (12), pp. 1239-1248

30 Vassolo, R.S., Anand, J., and Folta, T.B.: 'Non-Additivity in Portfolios of Exploration Activities: A Real OptionsBased Analysis of Equity Alliances in Biotechnology', Strategic Management Journal, 2004, 25, pp. 1045-1061

31 Folta, T.B., and O'Brien, J.P.: 'Entry in the presence of dueling options', Strategic Management Journal, , 2004, $25,(2)$, pp. 121-138.

32 Folta, T.B., and O'Brien, J.P.: 'Determinants of firmspecific thresholds in acquisition decisions', Managerial and Decision Economics, 2008, 29, (3), pp. 209-225

33 Folta, T.B.: 'Governance and Uncertainty: The Tradeoff Between Administrative Control and Commitment.', Strategic Management Journal, 1998, 19, pp. 1007-1028

34 Folta, T.B., and O'Brien, J.P.: 'Market versus Managerial Valuations of Real Options in Advances in Strategic Management', in Reuer, J., Tong, T. (Ed.) (Elsevier,New York, 2007), pp. 199-224

35 Kogut, B.: 'Joint Ventures and the Option to Expand and Acquire', Management Science, 1991, 37, (1), pp. 19-33

36 Denning, K.C., Hulburt, H., and Ferris, S.P.: 'Risk and Wealth Effects of U.S. Firm Joint Venture Activity', Review of Financial Economics, 2006, 15, pp. 271-285

37 Alonso, P.A., Palenzuela, V.A., and Herrero , G.F.: 'Real options as a component of the market value of stocks: evidence from the Spanish Stock Market', Applied Economics, 2005, 37, (14), pp. 1673-1691

38 Nooraie, M.: 'Factors Influencing Strategic DecisionMaking Processes', International Journal of Academic Research in Business and Social Sciences, 2012, 2, (7), pp. 662-682 
39 Kayo, E.K., Kimura, H., Patrocínio, M.R., and de Oliveira Neto, L.E.: 'Acquisitions, Joint Ventures or Arm's-Length Alliances?', BAR, Curitiba 2010, 7, (4), pp. 397-412

40 Lavie, D.: 'The competitive advantage of interconnected firms: an extension of the resource based view', Academy of Management Review, 2006, 31, (3), pp. 638-658

41 Colombo, M.G.: 'Alliance Form: A Test of the Contractual and Competence Perspectives', Strategic Management Journal, 2003, 24, pp. 1209-1229

42 Park, S.H., and Ungson, G.R.: 'The effect of national culture, organizational complementarity, and economic motivation on joint venture dissolution', Academy of Management Journal, 1997, 40, (2), pp. 279-307

43 Folta, T.B., and Ferrier, W.: 'The effect of national culture on partner buyouts in cross-border biotechnology alliances', Journal of High Technology Management Research, 2000, 11, (2), pp. 175-198

44 Luo, Y.: 'Antecedents and consequences of personal attachment in cross-cultural cooperative ventures', Administrative Science Quarterly, 2001, 46, (2), pp. 177200

45 Liu, H., and Rodriguez, R.M.: ' A fuzzy envelope for hesitant fuzzy linguistic term set and its application to multicriteria decision making', Information Sciences, 2013, 258, (10), pp. 220-238

46 Peng, D.H., Gao, C.Y., and Zhi-Fang Gao, Z.-F.: 'Generalized hesitant fuzzy synergetic weighted distance measures and their application to multiple criteria decision-making', Applied Mathematical Modelling, 2013, (37)

$47 \mathrm{Xu}$, Z.S., and Xia, M.M.: 'Distance and similarity measures for hesitant fuzzy sets', Information Sciences, 2011, 181, pp. 2128-2138

48 Wei, G., Zhao, X., and Lin, R.: 'Some hesitant intervalvalued fuzzy aggregation operators and their applications to multiple attribute decision making', Knowledge-Based Systems, 2013, 46, pp. 43-53

49 Zhao, X., Lin, R., and Wei, G.: 'Hesitant triangular fuzzy information aggregation based on Einstein operations and their application to multiple attribute decision making', Expert Systems with Applications, 2014, 41/4, (1), pp. 1086-1094

50 Ye, J.: 'Correlation coefficient of dual hesitant fuzzy sets and its application to multiple attribute decision making,' Applied Mathematical Modeling, 2014, 38, (2), pp. 659666

51 Zhang, Z.: 'Hesitant fuzzy power aggregation operators and their application to multiple attribute group decision making', Information Sciences, 2013, 234, pp. 150-181

52 Wei, G.: 'Hesitant fuzzy prioritized operators and their application to multiple attribute decision making', Knowledge-Based Systems, 2012, 31, pp. 176-182

53 Yager, R.R.: 'Prioritized aggregation operators', International Journal of Approximate Reasoning, 2008, 48, pp. 263-274

$54 \mathrm{Xu}, \mathrm{Z}$., and Xia, M.: 'Hesitant fuzzy entropy and crossentropy and their use in multiattribute decision-making', International Journal of Intelligent Systems, 2012, 27 (9), pp. $799-822$

55 Chen, T.Y., Chang, C.H., and Jui-fen, R.L.: 'The extended QUALIFLEX method for multiple criteria decision analysis based on interval type-2 fuzzy sets and applications to medical decision making', European Journal of Operational Research, 2013, 226, (3), pp. 615625

56 Chen, T.Y.: 'An interactive method for multiple criteria group decision analysis based on interval type-2 fuzzy sets and its application to medical decision making', Fuzzy Optimization and Decision Making, 2013, 12, (3), pp. 323-356

57 Chen, T.Y.: 'A linear assignment method for multiplecriteria decision analysis with interval type-2 fuzzy sets', Applied Soft Computing, 2013, 13, (5), pp. 2735-2748

58 Wang, W., Liu, X., and Qin, Y.: 'Multi-attribute group decision making models under interval type-2 fuzzy environment', Knowledge-Based Systems, 2012, 30, pp. 121-128

59 Chen, S.M., and Lee, L.W.: 'Fuzzy Multiple Criteria Hierarchical Group Decision-Making Based on Interval Type-2 Fuzzy Sets', IEEE Transactions on Systems, Man \& Cybernetics: Part A, 2010, 40, (5), pp. 1120-1128

60 Baležentis, T., and Zeng, S.: 'Group multi-criteria decision making based upon interval-valued fuzzy numbers: An extension of the MULTIMOORA method, „,' Expert Systems with Applications, 2013, 40, (2), pp. 543-550

61 Çelik, E., Bilisik, O.N., Erdogan, M., Gumus, A.T., and Baracli, H.: 'An integrated novel interval type-2 fuzzy MCDM method to improve customer satisfaction in public transportation for Istanbul', Transportation Research: Part E, 2013, 58, pp. 28-51

62 Mendel, J.M., and John, R.I.: 'Type-2 Fuzzy Sets Made Simple', IEEE Trans. on Fuzzy Systems, 2002, 10, pp. 117-127

63 Mendel, J.M., John, R.I., and Liu, F.L.: 'Interval type-2 fuzzy logical systems made simple', IEEE Transactions on Fuzzy Systems, 2006, 14, (6), pp. 808-821

64 Buckley, J.J.: 'Fuzzy hierarchical analysis', Fuzzy Sets and Systems 1985, 17, pp. 233-247

65 Chen, S.M., and Lee, L.W.: 'Fuzzy multiple attributes group decision-making based on the interval type-2 TOPSIS method', Expert Systems with Applications, 2010, 37, pp. 2790-2798

66 Torra, V., and Narukawa, Y.: 'On Hesitant Fuzzy Sets and Decision’. Proc. FUZZ-IEEE, Korea, August 20-24 2009 pp. Pages

$67 \mathrm{Xu}, \mathrm{Z}$., and Zhang, X.: 'Hesitant fuzzy multi-attribute decision making based on TOPSIS with incomplete weight information', Knowledge-Based Systems, 2013, 52 pp. 53-64.

68 Xia, M.M., and Xu, Z.S.: 'Hesitant fuzzy information aggregation in decision making', International Journal of Approximate Reasoning, 2011, 52, pp. 395-407

69 Zhang, N., and Wei, G.: 'Extension of VIKOR method for decision making problem based on hesitant fuzzy set', Applied Mathematical Modeling, 2013, 37, pp. 4938-4947

70 Kahraman, C., and Kaya, I.: 'A fuzzy multi criteria methodology for selection among energy alternatives', Expert Systems with Applications, 2010, 37, (9), pp. 6270-6281

71 Saaty, T.L.: 'The Analytic Hierarchy Process' (McGraw Hill, 1980. 1980) 
72 Laarhoven, P.J.M., and Pedrycz, W.: 'A fuzzy extension of Saaty's priority theory’, Fuzzy Sets and Systems, 1983, 11, pp. 229-241

73 Chang, D.Y.: 'Applications of the extent analysis method on fuzzy AHP', European Journal of Operational Research, 1996, 95, pp. 649-655

74 Zeng, J., Min, A., and Smith, N.J.: 'Application of fuzzy based decision making methodology to construction Project risk assessment', International Journal of Project Management, 2007, 25, pp. 589-600

75 Kahraman, C., Sari, I.U., and Turanoglu, E.: 'Fuzzy Analytic Hierarchy Process with Type-2 Fuzzy Sets'. Proc. Proceedings of the 19th International FLINS Conference2012 pp. Pages

76 Chiao, K.P.: 'Trapezoidal interval type-2 fuzzy set extension of Analytic Hierarchy Process,'. Proc. IEEE International Conference on Fuzzy Systems (FUZZIEEE), 10-15 June 20122012 pp. Pages

77 Sari, I.U., Oztaysi, B., and Kahraman, C.: 'Fuzzy AHP Using Type II Fuzzy Sets: An Application to Warehouse Location Selection', in Doumpos, M., and Grigoroudis, E. (Eds.): 'Multicriteria Decision Aid and Artificial Intelligence: Links, Theory and Applications' (Wiley, 2013), pp. 258-308

78 Huang, C., and Yoon, K.: 'Multiple attribute decision making methods and applications, in: A State-of-Art Survey,' (Springer, Verlag, 1981. 1981)

79 Roy, B.: 'Paradigms and Challanges', in Figueira, J., Greco, S., and Ehrgott, M. (Eds.): 'Multiple Criteria Decision Analysis: State Of The Art Surveys' (Springer, 2004)

80 Chen, S.J., Hwang, C.L., and Hwang, F.P.: 'Fuzzy multiple attribute decision making: Methods and applications' (Springer-Verlag, 1992. 1992)

81 G.S., L.: 'Fuzzy MCDM based on ideal and anti-ideal concepts', Europeal Journal of Operational Research, 1999, 11, (2), pp. 682-691

82 Chen, T.C.: 'Extensions of the TOPSIS for group decision-making under fuzzy environment,' Fuzzy Sets and Systems, 2000, 114, pp. 1-9

$83 \mathrm{Zhu}, \mathrm{B} ., \mathrm{Xu}, \mathrm{Z}$., and Xia, M.: 'Hesitant fuzzy geometric Bonferroni means', Information Sciences, 2012, 205, pp. 72-85

84 Qian, G., Wang, H., and Feng, X.: 'Generalized hesitant fuzzy sets and their application in decision support system', Knowledge-Based Systems, 2013, 37, pp. 357365

85 Beg, I., and Rashid, T.: 'TOPSIS for Hesitant Fuzzy Linguistic Term Sets', International Journal of Intelligent Systems, 2013, 28, (12), pp. 1162-1171 